\title{
Diretrizes para a assistência da terapia ocupacional na pandemia da COVID-19 e perspectivas pós-pandemia
}

\author{
Guidelines for occupational therapy assistance in COVID-19 pandemic and \\ post-pandemic perspectives
}

Marysia Mara Rodrigues do Prado De-Carlo ${ }^{1}$ (D), Cristiane Aparecida Gomes-Ferraz ${ }^{2}$ (D), Gabriela Rezende² (D), Luciana Buin ${ }^{3}$ (D), Diana Jasmim Amar Moreira4 (D), Karoline Lazzarotto de Souza ${ }^{5}$ (D), Angela Maria Sacramento ${ }^{(1 D}$, Walkyria de Almeida Santos ${ }^{7}$ (D), Paulo Vinicius Braga Mendes ${ }^{8}$ (D), Leticia Meda Vendrusculo-Fangel ${ }^{9}$ (D)

\section{RESUMO}

INTRODUÇÃO: A COVID-19 é uma doença altamente contagiosa, de apresentação recente, causada pelo novo coronavírus, denominado SARS-CoV-2 por ser da família SARS (Síndrome Respiratória Aguda Grave). São necessárias diretrizes cientificamente fundamentadas sobre as intervenções dos terapeutas ocupacionais no cuidado de pessoas com a COVID-19 e sobre as perspectivas de atenção pós-pandemia. OBJETIVO: Apresentar diretrizes e recomendações aos terapeutas ocupacionais sobre o manejo clínico de pacientes com COVID-19 em diferentes níveis de atenção à saúde, para favorecer a assistência segura e com qualidade técnico-científica. MÉTODO: Dez terapeutas ocupacionais de diferentes estados brasileiros, experts em suas áreas de atuação, reuniram-se, por meio de web conferências, para desenvolver diretrizes para a atuação do terapeuta ocupacional na pandemia da COVID-19. O público-alvo destas diretrizes é composto por terapeutas ocupacionais, gestores e outros profissionais interessados no conhecimento e nas ações da terapia ocupacional com pacientes com COVID-19 e seus familiares. Como ainda não existem estudos e revisões sistemáticas de evidências científicas relativas à terapia ocupacional na COVID-19, foram analisadas as melhores diretrizes e evidências disponíveis na literatura. Foi realizada uma ampla revisão de documentos nacionais e internacionais publicados sobre o tema, como artigos científicos e resoluções da Organização Mundial da Saúde e do Ministério da Saúde do Brasil. Foram também revisadas publicações disponibilizadas por sociedades ou organizações profissionais internacionais de terapia ocupacional, como a Federação Mundial de Terapeutas Ocupacionais, a Associação Americana dos Terapeutas Ocupacional, o Royal College of Occupational Therapists, do Reino Unido, e o Colegio Profesional de Terapeutas Ocupacionales de la Comunidad de Madrid, Espanha. RESULTADOS: As diretrizes reunidas nesta publicação não substituem as políticas institucionais e nacionais. Estão baseadas nos princípios da Ciência Ocupacional e nas melhores evidências disponíveis na literatura, balizadas pela experiência de todos os profissionais envolvidos na produção deste documento. Foram abordados temas como a privação ocupacional decorrente da pandemia e da estratégia de distanciamento social e os recursos técnicos recomendados para a promoção do desempenho ocupacional e manejo de dor e de sintomas

1. Professora associada (livre-docente) do Curso de Terapia Ocupacional, Departamento de Ciências da Saúde, Faculdade de Medicina de Ribeirão Preto da Universidade de São Paulo (RCS-FMRP-USP).

2. Terapeuta ocupacional, doutoranda pelo Programa de Enfermagem em Saúde Pública da Escola de Enfermagem de Ribeirão Preto da Universidade de São Paulo (EERP-USP).

3. Professora substituta do curso de Terapia Ocupacional do RCS-FMRP-USP.

4. Terapeuta ocupacional, responsável técnica do Serviço de Terapia Ocupacional da Rede D’Or São Luiz SA - Unidade Hospital Quinta D’Or.

5. Terapeuta ocupacional do Hospital de Base do Distrito Federal (HBDF).

6. Terapeuta ocupacional da Secretaria de Saúde do Distrito Federal (SES-DF).

7. Terapeuta ocupacional no Instituto de Oncologia Pediátrica do Grupo de Apoio ao Adolescente e à Criança com Câncer (GRAACC) da Universidade Federal de São Paulo (UNIFESP).

8. Terapeuta ocupacional do Centro de Reabilitação do Hospital Israelita Albert Einstein.

9. Professora adjunta do curso de Terapia Ocupacional da Faculdade de Ceilândia da Universidade de Brasília (FCE-UnB).

$\triangle$ Marysia Mara Rodrigues do Prado De Carlo. Departamento de Ciências da Saúde da Faculdade de Medicina de Ribeirão Preto - USP. Av. Bandeirantes, 3900 - Monte Alegre. CEP 14049-900. Ribeirão Preto (SP), Brasil.

marysia@fmrp.usp.br | Recebido em: 04/08/2020 | Aprovado em: 26/08/2020 
em diferentes contextos, com destaque para a atuação do terapeuta ocupacional na atenção básica, na atenção hospitalar e nos cuidados paliativos. CONSIDERAÇõES FINAIS: Dada a recente apresentação da COVID-19, há necessidade de constante atualização das informações e novas evidências científicas poderão ser publicadas. O raciocínio clínico é imprescindível para o planejamento e implementação da assistência aos pacientes e seus familiares ou cuidadores e será necessário o acompanhamento dos pacientes positivos para o SARS-CoV-2 para a verificação das consequências da COVID-19, das necessidades e demandas de reabilitação das pessoas acometidas, pós-hospitalização e pós-pandemia.

Palavras-chave: Terapia Ocupacional; COVID-19; SUS; Reabilitação; Cuidados Paliativos.

\section{ABSTRACT}

INTRODUCTION: COVID-19 is a highly contagious disease of a recent presentation, caused by the new coronavirus called SARS-CoV-2 because it belongs to the SARS family (Severe Acute Respiratory Syndrome). Scientifically grounded guidelines are needed on occupational therapists' interventions in caring for people with COVID-19 and on prospects for post-pandemic care. OBJECTIVE: To present guidelines and recommendations to occupational therapists on the clinical management of patients with COVID-19 at different levels of health care, to favor safe care with technical and scientific quality. METHOD: Ten occupational therapists from different Brazilian states, experts in their areas of expertise, met, through web conferences, to develop guidelines for the work of the occupational therapist in the pandemic of COVID-19. The target audience of these guidelines is composed of occupational therapists, managers, and other professionals interested in the knowledge and actions of Occupational Therapy with patients with COVID-19 and their families. As there are still no studies and systematic reviews of scientific evidence related to occupational therapy in COVID-19, the best guidelines and evidence available in the literature were analyzed. A wide review of national and international documents published on the subject, such as scientific articles and resolutions of the World Health Organization and the Ministry of Health of Brazil, was carried out. Publications made available by international occupational therapy societies or professional organizations, such as the World Federation of Occupational Therapists, the American Association of Occupational Therapists, the Royal College of Occupational Therapists from United Kingdom, and the Colegio Profesional de Terapeutas Ocupacionales de la Comunidad from Madrid, Spain. RESULTS: The guidelines in this publication do not replace institutional and national policies. They are based on the principles of Occupational Science and the best evidence available in the literature and the experience of all professionals involved in the production of this document. Topics such as occupational deprivation resulting from the pandemic and the strategy of social detachment and the technical resources recommended for the promotion of occupational performance and management of pain and symptoms in different contexts were addressed, with emphasis on the role of the occupational therapist in primary care, hospital care and palliative care. FINAL CONSIDERATIONS: Given the recent presentation of COVID-19, there is a need for constant updating of information, and new scientific evidence may be published. Clinical reasoning is essential for planning and implementing assistance to patients and their families or caregivers. It will be necessary to monitor patients who tested positive for SARS-CoV-2 to verify the consequences of COVID-19, their needs and demands of rehabilitation, post-hospitalization, and post-pandemic.

Keywords: COVID-19; Occupational Therapy; Hospital; Rehabilitation; Palliative Care.

\section{A PANDEMIA DA COVID-19 E PERSPECTIVAS PÓS-PANDEMIA}

DESCRIÇÃO: Este documento tem por objetivo apresentar diretrizes e recomendações para a atenção do terapeuta ocupacional, em diferentes níveis de assistência, no manejo clínico de pacientes com COVID-19. Fornece informações relevantes aos terapeutas ocupacionais e instituições sobre o papel potencial da terapia ocupacional no manejo de pacientes com COVID-19 confirmado e/ou suspeito, em diferentes níveis de atenção à saúde, com ênfase na atenção hospitalar. Foca no manejo e planejamento do cuidado para favorecer a assistência do terapeuta ocupacional segura e de qualidade.

PÚBLICO-ALVO: Terapeutas ocupacionais, gestores e outros profissionais interessados no conhecimento das ações da terapia ocupacional com pacientes com suspeita e/ou confirmados como portadores da COVID-19 e seus familiares. 
MÉTODO: Uma equipe de dez terapeutas ocupacionais de diferentes estados brasileiros - São Paulo, Rio de Janeiro e Distrito Federal - experts em suas áreas de atuação, reuniram-se por web conferências para desenvolver as recomendações publicadas neste documento de diretrizes para a prática clínica da terapia ocupacional na pandemia de COVID-19.

Diretrizes de prática clínica são ferramentas úteis para melhorar a provisão aos nossos pacientes dos melhores cuidados, com base nas melhores evidências disponíveis. (...) diretrizes de saúde e sua implantação adequada são do interesse das organizações nacionais, sociedades profissionais, provedores de serviços de saúde, elaboradores de políticas, pacientes e público em geral ${ }^{1}$.

Todos os membros do painel de diretrizes indicaram os temas sobre os quais melhores contribuições poderiam oferecer e contribuíram para a produção coletiva. Sua experiência inclui formação e atuação profissional em contextos hospitalares, particularmente em centros ou unidades de terapia intensiva (UTI), ambulatórios, unidades de internação hospitalar, centros de reabilitação e programas de atenção domiciliar oferecida por hospitais, assim como na atenção básica à saúde (contextos extra-hospitalares) e cuidados paliativos.

Foram identificadas publicações científicas com diretrizes recentemente desenvolvidas para o gerenciamento de pacientes críticos com COVID-19, produzidas por organizações internacionais, como a Organização Mundial da Saúde (OMS) e a Federação Mundial de Terapeutas Ocupacionais (WFOT), sociedades ou grupos de Terapia Ocupacional do Brasil e de outros países e profissões. O grupo de autores acordou que o trabalho está fundamentado em princípios da Ciência Ocupacional e, também, no documento: "Estrutura da Prática da Terapia Ocupacional: Domínio \& Processo", publicado pela Associação Americana de Terapia Ocupacional, em sua $4^{a}$ ed. americana $(2020)^{2}$ e em sua versão brasileira (2015) ${ }^{3}$.

Com a produção dessas diretrizes, os autores procuram responder a uma necessidade urgente de orientações para a prática do terapeuta ocupacional em tempos de COVID-19 e suas perspectivas para a pós-pandemia.

\section{INTRODUÇÃO}

A COVID-19 é uma doença altamente contagiosa e de apresentação recente, causada pelo novo coronavírus, denominado SARS-CoV-2 por ser da família SARS (Síndrome Respiratória Aguda Grave). De acordo com a Organização Mundial de Saúde 4 , cerca de $80 \%$ dos pacientes infectados pelo novo coronavírus (SARS-CoV-2) podem ser assintomáticos ou apresentar sintomas leves. Porém, cerca de $20 \%$ dos casos podem apresentar dificuldades respiratórias; desses casos, aproximadamente 5\% podem evoluir com sintomas respiratórios graves, que exigem cuidados intensivos com suporte ventilatório em unidades de terapia intensiva, ${ }^{5,6}$.

Em 3 de fevereiro de 2020, o Ministério da Saúde do Brasil publicou a Portaria no $188^{7}$, através da qual declarou Emergência de Saúde Pública de Importância Nacional (ESPIN) em decorrência da infecção humana pelo novo coronavírus, tendo por base o Decreto $n^{\circ} 7.616$, de 17 de novembro de $2011^{8}$.
O tratamento do paciente com suspeita ou infecção confirmada é baseado no controle de sintomas e tem como objetivo dar suporte clínico ao paciente. A principal medida preventiva preconizada é o isolamento social, que está alterando bruscamente a rotina de todas as pessoas, o que requer cuidados e orientações. As medidas tomadas para retardar a propagação do vírus estão causando uma interrupção generalizada na vida ocupacional, atingindo todas as faixas etárias ou ciclos de vida em todo o mundo por meio de recomendações governamentais ${ }^{9}$.

Para manter as pessoas protegidas contra o vírus, foram estabelecidas orientações sobre o distanciamento social e a quarentena domiciliar, com o fechamento de instituições educacionais, empresas e outros serviços. Foi necessário reorganizar ou readaptar as rotinas diárias da forma mais saudável possível, como home office ou aulas online no formato de educação à distância (EAD). Porém, muitas pessoas continuaram expostas à contaminação pelo novo coronavírus, seja porque realizam 
trabalhos considerados essenciais (como no caso dos trabalhadores de saúde), seja porque não aderiram à estratégia de distanciamento social, devido ao negacionismo em relação à pandemia ou porque necessitam sair de casa para trabalhar por necessidade de subsistência, uma vez que não obtiveram o apoio governamental necessário através dos mecanismos de seguridade social ${ }^{10}$.

Em todo caso, todos sofreram alterações na vida ocupacional devido à pandemia, o que pode afetar a saúde mental, o condicionamento físico e a saúde ocupacional, devido às restrições de mobilidade e de interações sociais ${ }^{11}$. Segundo a Federação Mundial de Terapeutas Ocupacionais (WFOT), os terapeutas ocupacionais reconhecem as mudanças que estão ocorrendo na maneira como as pessoas realizam suas ocupações como resultado da pandemia do COVID-19:

Os terapeutas ocupacionais compreendem a necessidade vital de acessar e usar medidas de controle de infecção combinadas com a necessidade de sustentar uma boa saúde psicológica, mental e resistência, a fim de permanecer seguros e saudáveis.

Os terapeutas ocupacionais trabalharão com as pessoas para desenvolver estratégias para facilitar o acesso contínuo a suas ocupações, que incluem, mas não se limitam ao indivíduo, família, comunidade, adaptação social e ambiental, saúde mental, tecnologia assistiva e telessaúde ${ }^{12,13}$.

O terapeuta ocupacional está apto para atuar com este novo perfil de clientes, sejam casos suspeitos ou confirmados, em diferentes linhas de cuidados, da atenção básica ao atendimento hospitalar especializado, segundo o Código de Ética Profissional e as diretrizes da Prática Baseada em Evidência (PBE).

Segundo o Código de Ética Profissional, os terapeutas ocupacionais têm o dever ético de atender à população inclusive durante as epidemias, como acontece na COVID-19, com todos os equipamentos de proteção individual (EPIs) necessários. Esta questão está contemplada na Resolução no 425, de 08 de julho de 2013, que estabelece o Código de Ética e Deontologia da Terapia Ocupacional:
Artigo 90 - Constituem-se deveres fundamentais do terapeuta ocupacional, segundo sua área e atribuição específica: [...]

$\mathrm{V}$ - colocar seus serviços profissionais à disposição da comunidade em caso de guerra, catástrofe, epidemia ou crise social, sem pleitear vantagem pessoal incompatível com o princípio de bioética de justiça ${ }^{14}$.

A Prática Baseada em Evidência (PBE) refere-se à busca, avaliação crítica e síntese das melhores evidências de pesquisa disponíveis sobre um determinado problema clínico, bem como à utilização e aplicação das evidências na prática para a tomada de decisões em assistência de saúde, de acordo com a experiência clínica e habilidades do profissional, com os valores e preferências da pessoa atendida (centrada no cliente e na família) e com o contexto onde ela vive. Antes de serem implementadas na prática clínica, as evidências devem ser analisadas criticamente e avaliadas quanto à sua qualidade, pertinência $e$ relevância, para que não sejam tomadas como verdades absolutas. Por fim, é necessária a avaliação dos resultados obtidos para a tomada de decisão sobre a melhor forma de cuidar do paciente e verificar se há necessidade de replanejar o tratamento ${ }^{15}$.

A prática clínica da terapia ocupacional, cientificamente fundamentada e baseada em evidências, é imprescindível para o oferecimento de intervenções com resultados e eficácia demonstrados. Nesse sentido, está ocorrendo uma movimentação internacional para a promoção da Terapia Ocupacional Baseada em Evidências (TOBE) ${ }^{16,20}$. Contudo, há necessidade urgente de produção de orientações e diretrizes para o atendimento aos pacientes acometidos pela COVID-19, baseadas nas melhores evidências científicas.

Dez terapeutas ocupacionais, de diferentes estados brasileiros - São Paulo, Rio de Janeiro e Distrito Federal - reuniram os principais conceitos e as melhores diretrizes disponíveis referentes à prática do terapeuta ocupacional no enfrentamento da COVID-19. Como ainda não existem estudos sistemáticos de evidências científicas relativas à terapia ocupacional na COVID-19, foi realizada uma ampla revisão de artigos científicos, guidelines e outros documentos publicados pela Organização Mundial da Saúde (OMS), pelo 
Ministério da Saúde do Brasil e por sociedades ou organizações profissionais nacionais e internacionais de terapia ocupacional, como a Federação Mundial de Terapeutas Ocupacionais (WFOT) e também de outras profissões ${ }^{21,22}$. Essas diretrizes baseiam-se em princípios da Ciência Ocupacional, no documento "Estrutura da Prática da Terapia Ocupacional: Domínios \& Processo", publicado pela Associação Americana de Terapia Ocupacional, em sua $4^{a}$ ed. americana $(2020)^{2}$ e na versão brasileira $(2015)^{3}$, dentre outros.

A seguir, serão abordados conteúdos fundamentais relacionados com as manifestações clínicas e o processo terapêutico-ocupacional em tempos de COVID-19.

\section{Manifestações clínicas da COVID-19}

Embora possam existir formas assintomáticas da COVID-19, pessoas acometidas podem progredir para a síndrome respiratória aguda grave, que apresenta alta letalidade e cujas principais manifestações clínicas ocorrem no nível respiratório, com comprometimento significativo da função respiratória devido ao dano alveolar difuso. Estudos atuais apontam que há fortes indícios clínicos de que o vírus SARS-COV-2 pode infectar também outros órgãos e tipos de células durante o curso da doença, incluindo células do sistema nervoso central ${ }^{23}$.

O Colegio Profesional de Terapeutas Ocupacionales de la Comunidad de Madrid, Espanha ${ }^{25}$, apontou que foram identificadas polineuropatias entre 50 e $80 \%$ dos pacientes na Unidade de Tratamento Intensivo (UTI), que causam fraqueza muscular e que podem interferir na capacidade respiratória e de deglutição. Em pacientes hospitalizados na China (primeiro país a identificar as manifestações da COVID-19) foram observados sintomas neurológicos como dor de cabeça, tontura, sonolência ou diminuição do nível de consciência, ataxia, acidente vascular cerebral isquêmico, crise convulsiva, hipogeusia (alteração do paladar), hiposmia (alteração do olfato) e neuralgias (diversas dores de origem neurológica) ${ }^{24}$.

Alterações no sistema musculoesquelético têm sido frequentemente observadas, tanto devido à infecção quanto pelo longo período de internação, somadas aos efeitos psicológicos de medo, perda de confiança, ansiedade e luto, impactando ainda mais no desempenho ocupacional. Será preciso avaliar outras hipóteses, como a possibilidade de ocorrência de uma resposta neuro-inflamatória persistente em pacientes sobreviventes da COVID-19 e a possibilidade do desenvolvimento de outras complicações, como a encefalopatia hemorrágica necrosante aguda em paciente adulto após dias de febre e estado mental alterado.

Portanto, além dos acometimentos manifestados nas fases agudas da COVID-19, estudos futuros, com follow up e grupos-controle adequados, serão necessários para conhecer suas consequências a longo prazo e quais as formas como as pessoas serão afetadas pós-pandemia, como apresentado na Figura 1.

De acordo com esse autor ${ }^{26}$, na evolução da pandemia devem acontecer 4 ondas:

- $\quad 1^{\text {a }}$ onda: crescimento da morbidade e mortalidade decorrentes da COVID-19, com necessidade de hospitalização, recuperação e reabilitação pós-hospitalização ou a possibilidade de morte;

- $\quad 2^{a}$ onda: ocorrência de novos casos COVID, possíveis reinfecções e agravamento de condições não-COVID devido às restrições de recursos disponíveis para tratamento;

- $\quad 3^{a}$ onda: agravamento de condições crônicas pré-existentes devido à interrupção, durante a pandemia, da assistência à pessoas que ficaram sem acesso a serviços de saúde;

- 4a onda: aumento de casos de adoecimento mental, trauma psíquico e transtorno de estresse pós-traumático (TEPT), esgotamento de recursos econômicos, dentre outros problemas decorrentes da pandemia.

Portanto, os terapeutas ocupacionais devem estar preparados tanto para o atendimento a pessoas no período agudo da doença, internadas em enfermarias ou em unidades de terapia intensiva (UTI) em contextos hospitalares, como também para cuidados de saúde mental, processos de reabilitação após alta hospitalar e pós-pandemia, a médio e longo prazos, ou em cuidados paliativos. 


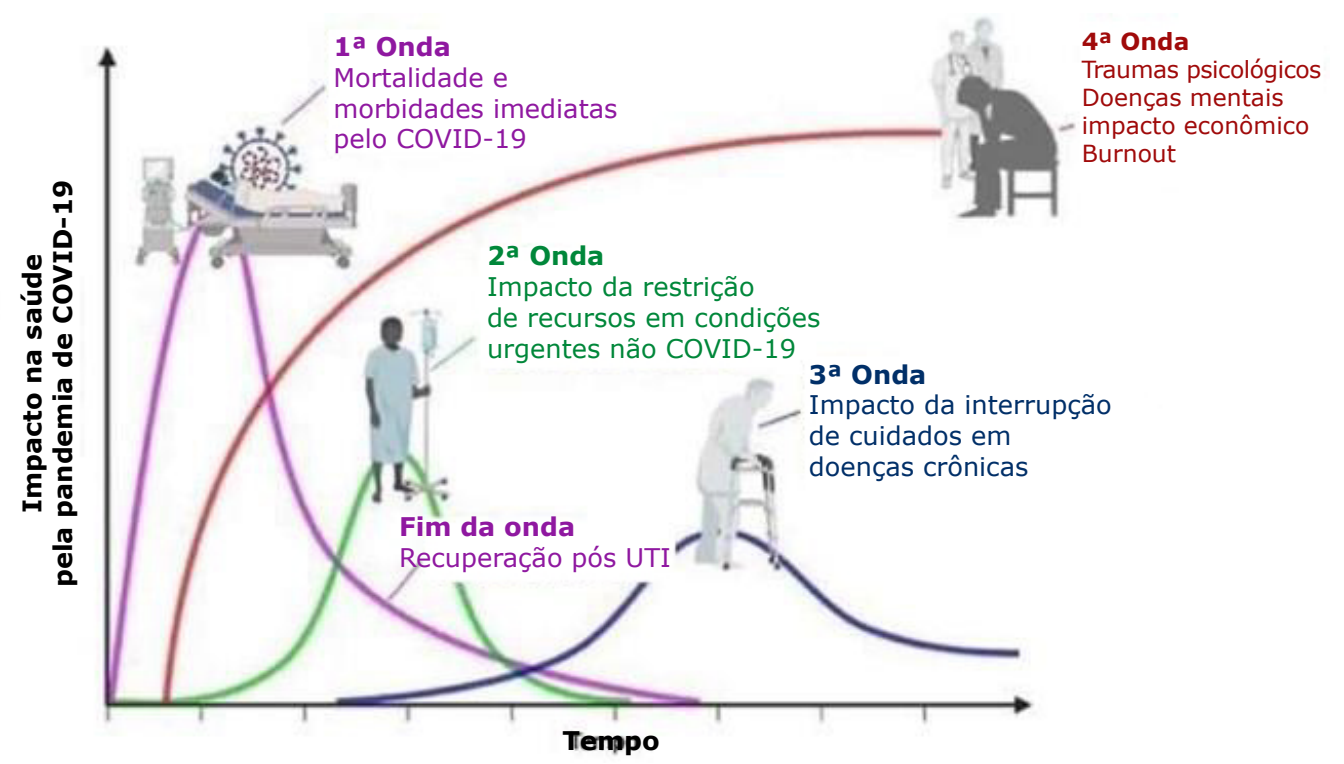

Figura 1: A quarta onda da Pandemia (The Pandemic's 4th Wave, Healthcare Leadership Blog, adaptado por Santos A.F.J.,2020 $)^{26}$.

\begin{abstract}
Terapeutas ocupacionais e outros profissionais de saúde estão observando uma série de déficits respiratórios, musculoesqueléticos, neurológicos e psicológicos em indivíduos que receberam tratamento hospitalar pelas consequências do vírus. Isso significa que, à medida que mais pessoas recebem alta do hospital, combinadas com as que estão se recuperando na comunidade, o número que requer reabilitação está crescendo rapidamente. É fundamental que essas pessoas tenham acesso à reabilitação, a fim de ter a melhor chance possível de maximizar sua recuperação ${ }^{27}$.
\end{abstract}

\section{Biossegurança}

Para a proteção do paciente atendido, do profissional e da sua equipe, devem ser seguidas normas e medidas de prevenção de contágio de maneira rigorosa, seguindo as orientações quanto ao uso de equipamentos de proteção individual (EPIs), como também na seleção de materiais e recursos terapêuticos ${ }^{28,29}$.

Qualquer atividade assistencial praticada por profissional de saúde deve contemplar as normas e os procedimentos de biossegurança, incluindo o manejo do paciente, higienização de materiais, equipamentos utilizados e do ambiente, dando preferência para aqueles que possam ser higienizados ou descartados caso necessário. Isso é essencial em tempos de COVID-19 e principalmente em contextos hospitalares.

Segundo Teixeira e Valle (2010), a biossegurança pode ser definida como "o conjunto de ações voltadas para a prevenção, minimização ou eliminação de riscos inerentes ao ambiente de trabalho, riscos que podem comprometer a saúde do homem, dos animais, do meio ambiente ou a qualidade dos trabalhadores envolvidos." ${ }^{30}$

A infecção hospitalar pode ser transmitida por falta de assepsia no meio ambiente, dos equipamentos e materiais utilizados, no paciente e da equipe que $o$ atende. A transmissão do agente infeccioso pode acontecer por contato direto ou indireto (através do contato com um objeto contaminado), por procedimentos invasivos ou pela realização de técnicas sem assepsia. São vias de transmissão: as gotículas (que atingem pequenas distâncias); aerossóis (que ficam suspensos no ar, podendo permanecer horas); veículos comuns (como alimentos, água, medicamentos ou produtos hemoterápicos contaminados); ou vetores mecânicos ou biológicos (como insetos, ratos e outros). Para a proteção dos profissionais no ambiente hospitalar, devem ser utilizadas as devidas precauções de contato, gotícula e ar. No caso da Covid-19, essas precauções são utilizadas de forma simultânea. 
Os procedimentos de controle de infecção hospitalar devem procurar antecipar a ocorrência de doenças ou acidentes, reconhecendo antecipadamente os riscos à saúde e aplicando medidas preventivas sempre que houver possibilidade de contaminação, como realizar a higienização adequada, principalmente a lavagem das mãos, a utilização correta de EPIs e a imunização, quando disponível ${ }^{31,32}$.

Tudo que entra no leito do paciente deve ser de uso único e descartado em lixeiras especiais de resíduos contaminados após cada atendimento ou internação. Os materiais e recursos terapêuticos utilizados pelos terapeutas ocupacionais não podem ser utilizados com outro paciente pelo risco de infeção cruzada, que pode ser definida como a infecção quando transferida de pessoa ou objeto para outra pessoa e que deve ser prevenida no contexto intra-hospitalar ${ }^{33}$.

Para a entrada no leito destes pacientes, o profissional necessita de um ambiente seguro de paramentação, onde o profissional deve seguir todas as normas da instituição onde trabalha. De acordo com a OMS, a paramentação adequada para o cuidado do paciente com COVID-19 inclui: uso de 2 (duas) luvas; capote ou macacão impermeável; duas toucas descartáveis; óculos de procedimento; máscara N95 / PFF2 (que contém um filtro especial para fazer uma barreira de proteção de ar); máscara cirúrgica por cima da outra; e protetor facial (face shield). O momento da desparamentação costuma ser o de maior risco de contaminação para os profissionais de saúde e, por esse motivo, exige o máximo cuidado na realização dos procedimentos necessários para a retirada dos equipamentos de proteção.

Por se tratar de uma doença com alto risco de contágio, os pacientes permanecem em isolamento até o final de sua internação, sem poder receber visita de seus familiares, o que acrescenta mais uma fonte de estresse e sofrimento. Posteriormente será discutida a utilização de recursos tecnológicos para o contato familiar, como a visita virtual, dentre outras.

Como a COVID-19 é uma doença nova, novos conhecimentos têm sido desenvolvidos cotidianamente como, por exemplo, sobre o tempo de permanência do vírus nos ambientes, de acordo com as propriedades de determinados materiais e superfícies $^{34}$. Portanto, a maneira de se proteger também pode mudar, o que exige constante atualização de informações junto aos serviços de Controle de Infecção Hospitalar (CCIH) e demais serviços de apoio aos profissionais de saúde.

\section{O PROCESSO TERAPÊUTICO- OCUPACIONAL E A COVID-19}

O cotidiano é a vida de todos os dias, de todos os homens, é a sucessão de acontecimentos vividos, incluindo espaços sociais, tempos diversos, pessoas e objetos variados. É no cotidiano que as pessoas expõem seu estilo de ser e constroem sua história pessoal e social ${ }^{35}$. Segundo A. Heller, "para a maioria dos homens, a vida é a vida cotidiana"36.

O termo ocupação refere-se a qualquer atividade intencional na qual a pessoa se envolve na sua vida cotidiana, como as ocupações de vida diária, educação, trabalho, descanso e sono, brincar, lazer e participação social. O envolvimento em ocupações estrutura a vida cotidiana, compreendida na perspectiva multidimensional e complexa, contribui para a saúde, para o bem-estar e qualidade de vida. Neste sentido "ocupação é usada para significar tudo que as pessoas querem, precisam ou devem fazer, seja de natureza física, mental, social, sexual, política ou espiritual, incluindo sono e descanso. Refere-se a todos os aspectos reais do fazer, ser e tornar-se humano e também ao de pertencer"3.

A ocupação é um princípio inerente à vida humana, que se manifesta por meio de diferentes formas de fazer e em diferentes contextos - temporal, físico e sociocultural. Ocupar-se é fundamental, é o que mantém o equilíbrio ocupacional através do ritmo de trabalho, descanso, lazer e sono. A vida ativa permite ao organismo se manter e se adaptar ao mundo real, em harmonia com sua própria natureza e agindo sobre a natureza ao seu redor ${ }^{37}$.

O desempenho ocupacional é a forma como as ocupações são realizadas. Ele é influenciado pelos fatores dos clientes (valores, crenças e espiritualidade, funções e estruturas do corpo); habilidades de desempenho (habilidades motoras, processuais e de interação social); padrões de desempenho (rituais, rotinas, hábitos e papéis); e pelos contextos e ambientes (social, cultural, pessoal, físico, temporal e virtual) onde ocorrem ${ }^{3}$. 
De acordo com a Ciência Ocupacional e segundo diversos documentos e modelos conceituais para a prática da terapia ocupacional, as ocupações são centrais para a identidade e para o senso de competência de quaisquer pessoas e têm um significado e valores particulares para elas, influenciando a forma como tomam decisões nas suas vidas ${ }^{38}$.

\section{Isolamento social e privação ocupacional}

O adoecimento e a hospitalização provocam interrupções na vida cotidiana e no isolamento social, dificultam a realização de ocupações valorizadas e podem causar mudanças no senso de identidade das pessoas; envolvem sentimentos de medo, incertezas, inadequação e dependência, com diminuição da qualidade de vida. As disfunções ocupacionais decorrentes do adoecimento, das incapacidades remanescentes, das mudanças na vida cotidiana e da participação social podem gerar quadros de dor e sofrimentos relacionados aos aspectos físicos, emocionais, sociais e espirituais ${ }^{29}$.

Durante a pandemia da COVID-19, têm sido observadas alterações no desempenho ocupacional, com mudança de hábitos e de rotinas, desestruturação de papéis ocupacionais, queda de produtividade e diminuição da eficácia nas ocupações. O distanciamento social e a ruptura do cotidiano devido à COVID-19 têm gerado grande estresse e desconforto ${ }^{39,40}$.

Quando o indivíduo não consegue engajar-se em ocupações de sua própria escolha, configura-se a condição de privação ocupacional ${ }^{41}$, que pode ser definida como:

estado de exclusão do envolvimento em ocupações necessárias e/ou significativas devido a fatores que estão fora do controle imediato da pessoa adoecida, o que pode levar a problemas físicos, dificuldades de sono, ansiedade e depressão, esgotamento e sentimentos de incapacidade e dependência e sofrimento espiritual ${ }^{42}$.

A privação ocupacional pode ter como consequências: sintomas depressivos, ansiedade, ausência do uso significativo do tempo, perda de autoestima e autoeficácia. Nessas condições, é necessário criar possibilidades para que, apesar do adoecimento e das limitações dele decorrentes, as pessoas possam manter um bom desempenho ocupacional através do engajamento em ocupações significativas e valorizadas que contribuam para o seu bem-estar e qualidade de vida e de sua comunidade ${ }^{43}$.

A exploração limitada do valor das ocupações, principalmente quando a pessoa está vivendo os últimos meses de vida, configura um desengajamento contínuo na vida ocupacional, com prejuízos para os papéis ocupacionais da pessoa adoecida e de seus familiares e/ou cuidadores. O papel ocupacional é uma posição na sociedade que contém uma série de responsabilidades e privilégios esperados. Os indivíduos estruturam o seu tempo para satisfazer suas necessidades pessoais e as demandas da sociedade por meio de seus papéis. É um componente essencial à vida, que faz emergir a autoidentidade ${ }^{44}$.

Estar engajado em ocupações produtivas é um determinante de saúde e bem-estar e pode contribuir para minimizar ansiedade, desconforto e a dor de pessoas em sofrimento ${ }^{45}$. Mesmo com o isolamento social, é importante focar naquilo que é possível fazer, procurar ocupações alternativas por meio das quais possam ser explorados conhecimentos e habilidades e manter um senso positivo de competência e valor próprio. É importante buscar o engajamento e o equilíbrio ocupacional através da reorganização do cotidiano para fornecer rotina e estrutura do cotidiano, aliviar o estresse e realocar recursos cognitivos, administrar o tempo, experimentar prazer e satisfação e fomentar a esperança, com ocupações que tenham sentido e significado para cada pessoa e que a representem pessoal e socialmente ${ }^{9}$.

O terapeuta ocupacional é o profissional capacitado para atuar frente à ruptura do cotidiano e busca, por meio de suas ações, promover a reorganização de rotinas, a readaptação de atividades de vida diária (AVDs) e a ressignificação de sentidos diante da situação e desafios atuais provocados pela pandemia do novo coronavírus.

A intervenção do terapeuta ocupacional, a fim de auxiliar os indivíduos a retomarem o desempenho ocupacional satisfatório no seu cotidiano, incluirá o uso de estratégias como gerenciamento 
ou adaptação das ocupações; o desenvolvimento de estratégias de enfrentamento; e, se necessário, a reabilitação ou cuidados paliativos em ambientes clínicos, do contexto hospitalar ou de contextos comunitários / territoriais, como em domicílio, na escola ou no local de trabalho. $O$ foco é permitir que os indivíduos participem de ocupações que tenham valor e significado para eles apesar das mudanças de rotina e do seu cotidiano, seja no contexto hospitalar ou no extra-hospitalar.

Durante o isolamento e distanciamento social, necessários para o enfrentamento da COVID-19, há necessidade de gerenciamento das condições de saúde e promoção de bem-estar através da reestruturação da rotina e reorganização da vida ocupacional, da adaptação do desempenho e da ressignificação das ocupações para a manutenção do equilíbrio ocupacional e prevenção ou minimização de problemas de saúde mental ${ }^{12,25}$.

Os terapeutas ocupacionais podem atuar durante a pandemia da COVID-19 em diferentes contextos assistenciais, que serão apresentados a seguir.

\section{Assistência comunitária e domiciliar no contexto da atenção primária à saúde}

A COVID-19 pode se manifestar por sintomas leves ou graves e pode levar a um período prolongado de hospitalização, em decorrência principalmente das síndromes respiratórias agudas ${ }^{46}$. Além do comprometimento respiratório, outros sintomas podem se manifestar, como alterações neurológicas, hematológicas, polineuropatia, miopatia, alterações musculoesqueléticas e eletrolíticas ${ }^{47,48}$.

O processo de hospitalização prolongado, com isolamento social, é permeado por inseguranças e medo, tanto por parte do paciente como de seus familiares, pelo desconhecimento da doença, o risco de morte e pela ruptura abrupta do cotidiano funcional do núcleo familiar. A assistência do terapeuta ocupacional é necessária para mitigar os efeitos deletérios das alterações funcionais e do desempenho ocupacional decorrentes do adoecimento e do período de isolamento e privação ocupacional ${ }^{49}$.

A Atenção Primária à Saúde (APS), de acordo com a Política Nacional de Atenção Básica, é a porta de entrada preferencial do Sistema Único de Saúde
(SUS) e tem como atributos: a longitudinalidade do cuidado, a integralidade, a coordenação, a centralidade na família, a orientação para a comunidade e a adequação cultural na atenção à saúde. É caracterizada como um conjunto de ações de saúde individuais, familiares e coletivas que envolvem promoção, prevenção, proteção, diagnóstico, tratamento, reabilitação, redução de danos, cuidados paliativos e vigilância em saúde, desenvolvida por meio de práticas de cuidado integrado, resolutividade e gestão qualificada, realizada com equipe interprofissional dirigida à população e demandas do território definido ${ }^{50-52}$.

Durante a pandemia por COVID-19, as Secretarias de Estado da Saúde (SES) estabeleceram planos de contingência e fluxos assistenciais, considerando que a maioria dos pacientes suspeitos ou confirmados passarão pela Atenção Primária à Saúde (APS), que confere um espaço privilegiado de gestão do cuidado das pessoas e tem um papel estratégico na Rede de Atenção à Saúde (RAS). A APS é a responsável pelo ordenamento e efetivação da integralidade do cuidado; é importante que apresente alta resolutividade, com qualificação do cuidado, incorporação de tecnologias leves e duras (diagnósticas e terapêuticas), além da articulação com os outros cenários das RAS.

As pessoas que recebem atenção comunitária e/ou domiciliar podem ter múltiplas e variadas necessidades a curto, médio e longo prazo, que exigirão uma abordagem em terapia ocupacional focada na ocupação. Intervenções direcionadas e universais chegarão até essas pessoas através de outros profissionais das equipes na atenção comunitária, com treinamento especializado para tal, assim como as necessidades vinculadas aos serviços sociais em comunidade.

A terapia ocupacional tem seu papel estruturado no cenário da APS, inserida nos núcleos ampliados de saúde da família e atenção básica (NASF$A B$ ). Esses núcleos são compostos por uma equipe interdisciplinar, de diferentes áreas do conhecimento, inclusive da terapia ocupacional, para atuar em conjunto com os profissionais das equipes de saúde da família (ESF). A sua finalidade é ampliar o escopo de ações da APS e contribuir para o aumento da resolubilidade, em tempo oportuno, à população e ao território assistido. Os núcleos contribuem também para o incremento da capacidade de análise e 
de intervenção sobre problemas e necessidades de saúde, tanto em termos clínicos quanto sanitários.

É responsabilidade do terapeuta ocupacional desenvolver atendimentos individuais, grupos, visitas domiciliares, educação permanente em saúde, matriciamento, reuniões, atuação interprofissional e intersetorial, apoio institucional à gestão, realização de diagnóstico situacional e identificação de agravos no território. Esse profissional é apto a colaborar nas intervenções para manutenção e melhoria do desempenho ocupacional, na independência, autonomia, ressignificação e reorganização do cotidiano, indicação e confecção de tecnologias assistivas, promoção da qualidade de vida e participação social, com a finalidade de propiciar o cuidado integral do usuário ${ }^{53}$.

O trabalho do terapeuta ocupacional na APS visa auxiliar o indivíduo e sua família na reorganização do seu cotidiano e nas readaptações que forem necessárias para a promoção do desempenho ocupacional em contexto domiciliar. $O$ isolamento social necessário devido à COVID-19 obriga a todos a reconhecer seu novo contexto de vida, a perceber as mudanças e a organizar suas ocupações e papéis ocupacionais (de mãe ou pai, filho, colega, amigo, trabalhador, etc.). Pode ser necessária também uma intervenção no ambiente domiciliar, para atender às novas demandas como: local de estudo para as crianças e adolescentes, e local de trabalho para os adultos em home-office.

Em condição de quarentena e isolamento social e para os casos suspeitos, a recomendação é que, mesmo na APS, a intervenção seja realizada por telefone ou uso de alguma outra ferramenta, como vídeo-chamada. Para os usuários que não estão em quarentena, caso haja a necessidade, é possível realizar visitas domiciliares e institucionais para a efetivação do atendimento ou matriciamento, desde que cumpridos os cuidados normativos de higienização e distanciamento entre paciente e terapeuta.

A intervenção do terapeuta ocupacional na APS, no cenário da COVID-19, envolve também:

- Acolhimento / demanda: é um dispositivo efetivo, pois facilita o acesso e favorece o vínculo e a intervenção em tempo oportuno; há o acolhimento no qual é realizada a triagem para determinar se o usuário é suspeito ou não.
Nos casos suspeitos, são objetivos do terapeuta ocupacional: orientar e auxiliar na organização da quarentena, no sentido de reorganização da dinâmica familiar e reestruturação da rotina com atividades significativas e oportunas que podem ser desenvolvidas em quarentena; orientar sobre o autocuidado e em relação aos cuidados de higienização, com a finalidade de garantir a saúde e minimizar o risco de contágio de outros residentes do domicílio.

- Monitoramento de pacientes com síndrome gripal, suspeitos e confirmados de COVID-19 na APS/ESF: o terapeuta ocupacional pode realizar o monitoramento dos pacientes que estão em quarentena, tanto em relação às suas condições clínicas, como para oferecer suporte na reorganização do cotidiano do paciente e das atividades do núcleo familiar.

- Suporte psicossocial: o terapeuta ocupacional pode oferecer suporte psicoemocional e social ao paciente que está em distanciamento social e que apresente demandas relacionadas ao manejo de sintomas e do sofrimento. Neste sentido, é importante avaliar o sofrimento psíquico (quadro de ansiedade, depressão, desesperança, crise existencial-espiritual etc.) e rastrear as ocupações e papéis ocupacionais modificados, perdidos ou desejados para um futuro próximo. O terapeuta ocupacional pode ainda organizar intervenção de suporte para a equipe da Unidade Básica de Saúde (UBS), propiciando, por exemplo, a escuta para os profissionais, e a oferta de práticas integrativas e complementares (PICs), como acupuntura, reiki, yoga, automassagem e técnicas de relaxamento e de redução de estresse (TRE). Intervenção com população em situação de abrigamento (crianças, pessoas com deficiência, população de rua) ou instituições de longa permanência para idosos (ILPI), pelo suporte tanto 
aos internos, equipe de saúde e gestores institucionais, pelo necessário matriciamento.

A assistência domiciliar é caracterizada por um conjunto de ações de promoção, prevenção e reabilitação, com a finalidade de se constituir como um ponto de cuidado estratégico, desenvolvido por uma equipe interdisciplinar que fomenta e garante a continuidade dos cuidados e está integrada às redes de atenção à saúde ${ }^{54,55}$. A perspectiva do processo de trabalho centrado na clínica ampliada possibilita a ampliação do grau de autonomia e da participação dos usuários no autocuidado e na compreensão sobre o processo saúde/enfermidade, pela capacidade estabelecer compromisso e contato com outros ${ }^{56}$.

A disponibilidade da atenção domiciliar permite o uso racional dos leitos e a desospitalização precoce, mitigando intercorrências clínicas e exposição à infeç̧ões hospitalares, com resolutividade em tempo oportuno e cuidado centrado no paciente. No contexto da pandemia do coronavírus, a assistência extra-hospitalar permite o cuidado continuado, exercido em ambiente domiciliar. Destaca-se a interação da assistência hospitalar com a domiciliar para o êxito e continuidade do cuidado. Neste sentido, o ponto inicial da assistência extra-hospitalar se dá através do projeto de desospitalização e suporte familiar para o retorno do paciente ao domicílio ${ }^{57}$.

O gerenciamento do Projeto de Desospitalização Precoce envolve: gestão da alta, suporte para o cuidado, mapeamento do território em relação a serviços de saúde e equipamentos sociais que possam ser acionados, avaliação do ambiente domiciliar e familiar, bem como da rede e suporte familiar do paciente. Esta ação tem como objetivo primordial disponibilizar leitos clínicos para os pacientes que necessitem de internação por complicações da COVID-19, porém mantendo a qualidade da assistência e cuidado integral ${ }^{58}$.

Considerando os diferentes níveis gravidade que a COVID-19 pode causar, o paciente pode apresentar comprometimentos variados em sua capacidade funcional. Estudos apontam que na Síndrome Respiratória Severa (SARS) o paciente pode cursar com comprometimento respiratório importante, período prolongado de imobilização, perda da mobilidade, bem como declínio da habilidade cognitiva, em especial na população idosa ${ }^{59}$. No aspecto psicossocial, há um aumento dos quadros de estresse, ansiedade e depressão, tanto no momento da internação, como até um ano após a alta, o que define a fase crônica da doença ${ }^{60}$.

$\mathrm{Na}$ assistência aos pacientes com COVID-19, que cursam com SARS ${ }^{61}$, estes podem apresentar necessidade da intervenção da terapia ocupacional na fase pós alta e crônica, em virtude do tempo prolongado de internação, pelo comprometimento do desempenho da capacidade funcional (autonomia e independência) e dos aspectos psicossociais, sendo todos fatores que interferem diretamente na qualidade de vida do paciente e familiares.

$O$ reconhecimento do ambiente domiciliar como um espaço de cuidado estendido, do contexto extra-hospitalar, propicia a criação de um cenário de assistência da terapia ocupacional, tendo como atores o paciente (usuário), a família/cuidador e o profissional de saúde ${ }^{62}$.

Segundo a AOTA ${ }^{2,3}$, é da competência do terapeuta ocupacional apoiar o envolvimento e a participação do paciente, bem como a análise e compreensão da ocupação, habilidades de desempenho, do ambiente e contextos, permeado por um processo de avaliação, intervenção e acompanhamento do cuidado longitudinal. Portanto, o terapeuta ocupacional deve possuir a base do conhecimento para auxiliar o paciente e a equipe no processo de desospitalização e no acompanhamento longitudinal, no ambiente extra-hospitalar.

Para a identificação das necessidades prioritárias de cada paciente, é essencial que o terapeuta ocupacional realize uma avaliação dos componentes e áreas do desempenho ocupacional, histórico ocupacional, histórico da doença atual, avaliação integral e elabore um plano terapêutico singular (PTS).

As intervenções que competem ao terapeuta ocupacional no contexto extra-hospitalar são variadas, porém todas objetivam melhora no desempenho ocupacional, diminuição dos efeitos da hospitalização e alta orientada e segura. A necessidade de fomentar a independência, a autonomia e a plena condição para o desempenho ocupacional, dos pacientes em convalescença pela COVID-19, traz à luz a crescente demanda de atuação do terapeuta ocupacional no contexto extra-hospitalar, após as altas taxas de infecção por esse vírus. Ações sugeridas: 
- monitorar e capacitar os familiares em relação aos sinais e sintomas de agravamento do quadro: fadiga, cansaço, sobrecarga respiratório;

- realizar diagnóstico situacional das rotinas e desempenho ocupacional do paciente e membros familiares;

- auxiliar a família na escolha do ambiente para realização da quarentena considerando as condições de biossegurança: ventilação, circulação, realização do autocuidado, em especial banho e alimentação; no caso da impossibilidade de uso do banheiro de modo independente, orientação e treinamento em relação aos procedimentos e produtos para a higienização adequada;

- orientar sobre o uso de máscara (situações recomendadas) e soluções recomendadas para a higienização da casa, bem como o descarte do lixo;

- indicar e confeccionar adaptações para utensílios necessários para o desempenho das atividades de vida diárias (AVDs), por exemplo: adaptação de talher, pente e outros;

- auxiliar na estruturação de uma rotina com ocupações de interesse para o paciente, com a finalidade de prevenir ou minimizar situações que gerem maior ansiedade, ociosidade e principalmente que não causem fadiga e possível agravamento do quadro;

- reconstruir a rotina ocupacional do paciente com ocupações significativas para o mesmo;

- estimular a manutenção da independência e autonomia nas AVDs;

- estimular a manutenção dos vínculos sociofamiliares, dentro dos limites da biossegurança para o paciente e familiares;

- orientar, caso seja possível, a manutenção das atividades laborais (teletrabalho) de forma estruturada e segura;

- promover o empoderamento familiar, por meio de orientações, no processo de reestruturação da rotina e do desempenho ocupacional de cada membro familiar;

- orientar familiares e/ou cuidadores sobre a necessidade de o paciente participar ativamente do processo de reabilitação;

- auxiliar familiares e/ou cuidadores a enfrentar suas próprias mudanças de papéis e ocupações que interferem nos cuidados dos pacientes;

- estimular a manutenção e retomada dos papéis ocupacionais e a reestruturação do cotidiano pós hospitalização;

- discutir com paciente e familiares sobre objetivos, metas e estratégias para melhor enfrentamento e reconstrução das ocupações e cotidiano pós-pandemia;

- $\quad$ orientar, no momento da alta, sobre os serviços de acompanhamento ambulatorial, caso julgue necessário para os quadros avaliados;

- acionar a equipe de cuidados paliativos para suporte ao paciente e familiares, favorecendo o processo de despedi$\mathrm{da}$, finalização de projetos de vida e manutenção do conforto e qualidade de vida, nos casos que ocorrer evolução para a condição de ausência de possibilidades de modificação da doença (sem possibilidade de cura).

Estas orientações podem ocorrer no cenário da atenção primária à saúde ou mesmo no ambiente hospitalar, nos pontos de assistência de emergência para o COVID-19, além da interface com a assistência extra-hospitalar, que será abordada a seguir.

\section{Atenção hospitalar de nível secundário ou terciário}

A especialidade profissional dos terapeutas ocupacionais em Contextos Hospitalares foi reconhecida pelo Conselho Federal de Fisioterapia e Terapia Ocupacional através da Resolução no 371 de 06 de novembro de $2009^{63}$ e foi disciplinada pela Resolução no 429 de 08 de julho de $2013{ }^{64}$. Foram definidas as competências do terapeuta ocupacional 
especialista em contextos hospitalares e as áreas de atuação da especialidade, dentre elas a de cuidados paliativos.

Dentre as atribuições previstas para serem exercidas pelos especialistas terapeutas ocupacionais em contextos hospitalares, além da assistência direta aos pacientes em hospitais gerais ou especializados, de média ou elevada complexidade de atenção à saúde e em todas as fases do desenvolvimento ontogenético, estão a responsabilidade técnica, o gerenciamento de serviços, a coordenação e supervisão, gestão, direção, chefia, consultoria, auditoria, perícia, ensino e pesquisa.

\section{Durante a internação hospitalar ou em aten-} ção ambulatorial, o terapeuta ocupacional deve atuar em parceria com a equipe multiprofissional. Dentre as intervenções destacam-se: avaliação, abordagem individual, orientações às famílias e cuidadores; prescrição e treinamento de produtos de apoio e adaptações; ações de humanização e enriquecimento ambiental; intervenções com abordagem multidisciplinar; orientação e programação de alta hospitalar ${ }^{65}$.

Para a realização da avaliação inicial do paciente com COVID-19, Thomas e colaboradores $^{21}$, sugerem que a abordagem pode ser feita através de uma triagem para elencar as demandas sem o contato direto com o paciente, podendo realizar rastreio através de documento em prontuário e demandas levantadas pela equipe. O contato com familiares e/ou cuidadores poderá ser feito, também, através de ligação telefônica. Dados importantes a serem elencados são: histórico ocupacional, histórico clínico e situação sócio familiar para definição de metas terapêuticas. Após a abordagem inicial pode-se utilizar avaliações padronizadas para mensurar sintomas como: fadiga, dispneia, AVDs, depressão, ansiedade, função cognitiva, qualidade de vida e repertório ocupacional.

Objetivos terapêuticos a serem trabalhados com paciente com COVID-19 no processo de internação hospitalar são:

- minimizar o impacto gerado pela hospitalização, principalmente os efeitos do isolamento social e privação das capacidades sensório-motoras, cognitivas e socioemocionais;
- melhorar a qualidade de vida durante o período de hospitalização, por meio do resgate das ocupações e participação social;

- $\quad$ promover participação e desempenho nas AVDs de forma segura, prevenindo a dessaturação de oxigênio e a redução da dispneia e fadiga na realização das atividades;

- estimular a independência funcional e ocupacional com uso de técnicas de conservação de energia, simplificação das tarefas e estratégias de adaptação de apoio e modificação do ambiente;

- favorecer a comunicação alternativa durante período de intubação;

- $\quad$ abordar aspectos psicossociais e promover a saúde mental dos pacientes e cuidadores como ansiedade e depressão;

- favorecer atividades de lazer de acordo com os interesses do paciente $\mathrm{e}$ situação clínica, dentro do isolamento;

- motivar as pessoas acometidas para a realização das ocupações significativas;

- contribuir com o planejamento e preparação da alta hospitalar, com segurança e apoio de cuidadores;

- $\quad$ oferecer estimulação sensorial - olfato e paladar - para recuperação precoce.

Após realização da avaliação inicial, é necessário estabelecer quais são demandas prioritárias a serem trabalhadas durante o período de internação, como: limitações na capacidade funcional que impactam a independência nas AVDs como, por exemplo, a realização das atividades de autocuidado após a alta da UTI; posicionamento inadequado no leito; alterações cognitivo-comportamentais; alterações no olfato e paladar; isolamento sócio familiar, dentre outras ${ }^{25}$.

Pacientes diagnosticados com COVID-19 encontram-se em isolamento durante o período de internação, sendo importante destacar que, sempre que possível, devem ser oferecidos recursos para que possam se manter ativos. Assim, o terapeuta ocupacional pode planejar suas intervenções de modo a superar a privação ocupacional e assim manter o equilíbrio ocupacional, buscando minimizar o aparecimento de disfunções sensório-motoras, perceptivas e psicossociais. 
Para evitar a redução do desempenho ocupacional, deve-se incluir também a necessidade de superação do medo em realizar algumas ocupações, como as atividades de autocuidado e o caminhar, as quais são afetadas no contexto da internação hospitalar, pela alta demanda energética e diminuição da tolerância à ocupação.

De acordo com a literatura sobre a atuação do terapeuta ocupacional durante a fase de hospitalização, observam-se algumas abordagens a serem utilizadas ${ }^{25,} 27$.

\section{Adequação postural}

- orientar o posicionamento no leito e uso de tecnologias para prevenção de lesões por pressão;

- avaliar a necessidade de uso de talas/ órteses;

- propor estratégias de mobilização precoce para que o paciente consiga desempenhar sozinho.

\section{Capacidades sensório-motoras}

- favorecer o contato visual dos membros, evitando o negligenciamento unilateral;

- promover a estimulação neurofuncional durante a realização das atividades de alimentação, autocuidado e de lazer no leito, por exemplo;

- realizar a estimulação tátil, cinestésica e olfativas na realização das AVDs, como aplicação de creme, colônia de banho, etc.;

- $\quad$ usar de mobilização passiva, ativo assistida, mudanças de decúbitos e treinos de transferências, para favorecer a mobilização precoce e diminuir impactos tardios nas capacidades sensório motoras;

- realizar a estimulação auditiva com uso de músicas, por exemplo, a fim de resgatar histórias de vidas e desejos pessoais;

- promover a adequação ambiental, por meio de controle de estímulos sonoros, luminosos e outros que possam ser prejudiciais ao sujeito.

AVDs

- usar de técnica de conservação de energia e simplificação das tarefas para promover a manutenção ou retomada das AVDs;

- realizar o ajuste do posicionamento funcional e modificações necessárias, para facilitação de suas realizações;

- promover estratégias para a facilitação da alimentação após extubação da ventilação mecânica.

Intervenção cognitiva e abordagem sobre delirium

- informar ao paciente de forma clara e adaptada à situação e a capacidade cognitiva;

- facilitar a conversa entre o paciente, a equipe e a família, envolvidos no processo;

- utilizar de recursos tecnológicos (telefone, televisão, tablet) para manter e estimular a atividade cognitiva e adaptada à capacidade da pessoa;

- promover a orientação espaço temporal (uso de calendários e fotos, por exemplo);

- possibilitar um espaço de vivência de atividades de lazer significativas que reforcem a capacidade cognitiva: jogo de palavras, livros, jogos cognitivos, jornais e revistas;

- orientar aos familiares e acompanhantes sobre estímulo à participação das atividades, de chamada telefônica, chamada de vídeo, orientações, recordações;

- $\quad$ estabelecer rotina em ambiente hospitalar com programação das atividades, na medida do possível, respeitando a organização e infraestrutura hospitalar; promover atividades de higiene do sono.

\section{Bem-estar emocional}

- possibilitar a realização de estratégias de alívio do stress, tais como: meditação; treino de respiração, técnicas de relaxamento, desenvolvimento de ocupações significativas, atividades expressivas, entre outros.

- realizar o manejo da dispneia, utilizando estratégias como técnicas de 
respiração, relaxamento e/ou conservação de energia.

- promover a participação e integração social, por meio de uso de recursos para comunicação com a família (telefone, vídeo chamada, redes sociais, etc.).

- possibilitar a humanização e personalização do ambiente.

- gerenciar o acesso às ocupações que gerem ansiedade como, por exemplo, assistir ao noticiário.

\section{Estimulação olfato e paladar}

- promover a estimulação sensorial, por meio de exercícios e atividades de estímulo olfatório e de paladar.

Segundo o Ministério da Saúde ${ }^{66}$, os pacientes elegíveis à alta hospitalar devem apresentar, além do exame negativo para Covid-19, alguns padrões clínicos, como estabilidade hemodinâmica, boa aceitação da dieta oral, ausência de febre e não apresentar suplementação de oxigênio, além de sintomas de taquidispneia e hipóxia.

Diante desse contexto, durante a internação do paciente na enfermaria, o terapeuta ocupacional realiza a abordagem para a preparação de alta, tendo como objetivo antecipar e/ou identificar as dificuldades encontradas em ambiente domiciliar, utilizando recomendações sobre retorno às atividades em rotina extra-hospitalar, visando organização da rotina do paciente e restabelecimento dos papéis ocupacionais ${ }^{67}$.

Algumas intervenções a serem utilizadas para a preparação de alta:

- identificação e organização da rede de apoio (rede social de suporte);

- $\quad$ orientações sobre cuidados de riscos à saúde (cuidados de higiene e proteção individual devido à contaminação do COVID-19);

- redação de relatórios;

- realização de reuniões familiares;

- $\quad$ adaptações ambientais.

Durante a internação em Unidade de Terapia Intensiva (UTI) - Na UTI são internados os pacientes graves, em geral hemodinamicamente instáveis, necessitando de drogas vasoativas e ventilação mecânica. Os pacientes permanecem em monitorização hemodinâmica invasiva ou não, de maneira contínua e recebem suporte avançado de vida, com alta tecnologia e funcionamento 24 horas, com equipe especializada de unidade hospitalar de alta complexidade. O terapeuta ocupacional compõe essa equipe de atendimento especializado, podendo atuar desde a chegada do paciente nesta unidade até a sua alta68-70.

O paciente com Síndrome Respiratória Aguda Grave (SARS), com complicações da COVID-19 e pneumonia avançada, muitas vezes é internado na UTI já em ventilação mecânica proveniente do setor de Emergência. Nestes casos, inicia-se a avaliação em TO visando o uso de tecnologia assistiva que poderá auxiliar como recurso terapêutico para favorecer o posicionamento no leito, ou outras adaptações necessárias neste momento ${ }^{71,72}$.

Quando os parâmetros respiratórios continuam insuficientes mesmo com todos os ajustes conforme protocolo preexistente na SARS, sugere-se utilizar a ventilação protetora em decúbito prono por no mínimo 16 horas $^{73,74}$. Essa posição facilita a expansão pulmonar ventral, diminuindo a pressão intra-abdominal, promovendo alterações hemodinâmicas ${ }^{75}$. O terapeuta ocupacional, além de participar na manobra de pronação do paciente, poderá confeccionar coxins para evitar lesões por pressão, decorrentes do grande tempo na mesma posição.

Quando se inicia a retirada de sedação, muitas vezes o paciente ainda está em ventilação mecânica, começando o desmame ventilatório. $O$ terapeuta ocupacional avalia o paciente para o uso da prancha de comunicação alternativa e suplementar. Inicia o treinamento do uso das pranchas elaboradas após avaliação, sempre orientando equipe e paciente ${ }^{76}$.

Concomitantemente ao treinamento da prancha, o terapeuta ocupacional realiza avaliação funcional, observando déficits motores e cognitivos decorrentes do período prolongado de internação, que comumente acontece pelo COVID-19. $\mathrm{Na}$ maioria dos casos, observa-se incapacidade funcional, junto com cansaço significativo. Nesses pacientes, o atendimento deverá ser adaptado junto ao treinamento de AVDs, com técnicas de conservação de energia.

Devido ao longo período de internação, o paciente deve ser avaliado para rastreio de prejuízos cognitivos através de avaliações específicas, 
pois existe uma alta prevalência de delirium na UTI que podem causar comprometimento funcional como um todo ${ }^{77}$.

Por meio da realização das estimulações necessárias, o paciente grave com COVID-19 consegue sair dessa unidade apresentando uma melhora significativa de qualidade de vida e capacidade funcional quase que restabelecida.

A intervenção do terapeuta ocupacional nas fases de internação hospitalar busca promover a qualidade de vida do paciente visualizando, além da ampliação da capacidade funcional desses indivíduos, o desenvolvimento de programas de intervenção que possam abranger a complexidade dos aspectos referidos, procurando investir na ambientação, na humanização e no cotidiano da clientela internada no hospital e de suas interfaces com a família e equipe. Nestes primeiros momentos de cuidado, o programa de reabilitação inclui exercícios terapêuticos, estratégias de posicionamento, educação em saúde e treinamento e orientação quanto às $\mathrm{AVDs}^{78}$.

No cenário hospitalar, os pacientes com COVID-19 têm necessidades complexas que requerem intervenção especializada e direcionada durante a internação em enfermaria de casos agudos, unidades de cuidados críticos, em serviços de terapia intensiva ou através de atenção ambulatorial. As pessoas que estão em internações hospitalares podem ter necessidades de reabilitação a curto, médio e longo prazos ou de cuidados paliativos. Possivelmente será necessário abordar também as consequências pós-COVID-19 através do acompanhamento de pessoas que se recuperam do vírus em contextos ambulatoriais e pela atenção primária em saúde. É importante contemplar também a colaboração com os colegas nos serviços comunitários e a comunicação entre os locais, pois devem ser incentivadas para fornecer um serviço eficaz e eficiente aos indivíduos.

\section{Reabilitação}

Pacientes com COVID-19 vivenciam múltiplas fases de cuidado. Quando evoluem para um estágio mais grave da doença, necessitam de cuidados hospitalares incluindo internação na UTI na fase aguda, devido à síndrome respiratória aguda, que corresponde a cerca de $32,8 \%$ das internações ${ }^{79}$. Após o período de internação na UTI os pacientes podem apresentar diversos agravos funcionais com impactos biopsicossociais, exigindo cuidados de longo prazo durante a recuperação em casa, após a hospitalização ${ }^{80}$.

Para esses casos a reabilitação é vista como uma intervenção complexa e refere-se a um processo focado em minimizar o efeito incapacitante das deficiências de um indivíduo, promovendo e otimizando a independência funcional nas AVDs e maximizando as oportunidades de participação significativa na sociedade ${ }^{81}$. É provável que algumas pessoas que se contaminaram com a COVID-19, mas que não foram hospitalizadas, também tenham necessidades de reabilitação e apoio, porém, a extensão dessa necessidade ainda não foi devidamente compreendida.

Pacientes diagnosticados com a COVID-19 podem apresentar uma série de comprometimentos funcionais em função das manifestações clínicas da doença, assim como pelo período de internação. Há uma necessidade urgente de orientar as práticas de reabilitação durante a crise da COVID-19, seguindo as melhores evidências disponíveis, incluindo consulta à comunidade clínica ${ }^{82}$.

Muitos pacientes que sobrevivem à COVID-19 necessitarão de reabilitação para tratar sequelas funcionais advindas da infecção, para ampliar o status funcional e prepará-los para a alta e reintegração na comunidade. Os déficits gerados pela síndrome respiratória aguda podem ter efeitos complexos e de longa duração, e exigem que o paciente seja assistido por uma equipe multiprofissional para a implementação do plano terapêutico e avaliações constantes mesmo após o período de internação ${ }^{83}$.

Como profissionais atuantes na reabilitação, os terapeutas ocupacionais têm papel importante diante da recuperação funcional dos pacientes com COVID-19 em todas as fases de cuidado, especialmente pela visão holística própria da profissão.

De acordo com o Royal College of Occupational Therapists (2020), seja nos estágios iniciais do tratamento agudo ou quando uma pessoa recebe alta, podem ser identificadas formas de acometimento, como sequelas ou deficiências residuais, com comprometimentos físicos relacionados a polineuropatia do paciente crítico, fadiga e fraqueza muscular global, comprometimento da fala e da deglutição pós 
intubação, que podem levar também a limitação na comunicação do paciente, sendo necessária a utilização de recursos de comunicação alternativa ${ }^{27}$.

Segundo o Colegio Profesional de Terapeutas Ocupacionales de la Comunidad de Madrid (2020), a fadiga também está relacionada às alterações cardiopulmonares, pois o paciente enfrenta sintomas como a falta de ar, menor tolerância ao exercício, hipotensão postural, dessaturação rápida de oxigênio durante o esforço, padrões respiratórios disfuncionais e hiperventilação. Além dos sintomas de ordem física após a infecção da COVID-19, alterações neurológicas e psicológicas podem ocorrer afetando o nível de consciência do paciente, déficits de atenção e concentração, culminando na diminuição da autoconfiança, quadros de ansiedade, humor deprimido e ataques de pânico ${ }^{25}$.

Em meio à pandemia e em função da COVID-19, a presença de sequelas implica em maiores desafios para as pessoas infectadas. O processo de reabilitação deve iniciar-se assim que o paciente adquirir condições clínicas para a execução do protocolo de atividades propostas pelo terapeuta ocupacional, com o objetivo de desenvolver um processo terapêutico personalizado e centrado nas necessidades individuais, para auxiliar na recuperação dos impactos físicos, emocionais, sociais e espirituais decorrentes do adoecimento e do tratamento.

A reabilitação pós COVID-19 poderá ser pautada nos aspectos inerentes à pessoa, ao contexto e ao ambiente para a formulação do plano terapêutico. Ao avaliar um paciente, todos os aspectos inerentes à pessoa são considerados, incluindo as ocupações, os fatores dos clientes, as habilidades de desempenho, os padrões de desempenho, bem como contexto e ambiente. Todos são de igual valor, pois juntos eles interagem para influenciar a identidade ocupacional, a saúde, o bem-estar e a participação do cliente/paciente na vida².

A terapia ocupacional deve compor a equipe de reabilitação da COVID-19, seja ela realizada na comunidade, no hospital ou em um centro de reabilitação. O trabalho do terapeuta ocupacional potencializará as capacidades funcionais do paciente, estimulará as capacidades residuais e compensará os déficits funcionais para resultar na integração do paciente na sociedade conforme a sua limitação funcional, com o maior grau possível de autonomia e independência ${ }^{84}$.
O processo de reabilitação pode ser estruturado segundo alguns passos, para permitir a adequada compreensão do quadro clínico e funcional do paciente infectado pela COVID-19:

Avaliação: Os passos iniciais da avaliação pré-reabilitação devem abordar diferentes aspectos das ocupações do paciente, como básicas do cotidiano (autocuidado e alimentação), produtivas (atividade laboral, educação e gestão financeira) e lazer. Por meio da utilização dessa abordagem o terapeuta ocupacional tem a possibilidade de determinar os componentes de desempenho afetados pela COVID-19 e então permitir a melhora funcional.

A Associação Americana de Terapia Ocupacional (AOTA) ${ }^{3}$ orienta a utilização de uma abordagem Top-Down na obtenção de dados durante a avaliação, ou seja, ela se inicia pela construção do perfil ocupacional e análise da competência ocupacional da pessoa. Tal abordagem sugere que os terapeutas reconheçam o que as pessoas querem e precisam fazer, ao invés da aplicação de um instrumento de avaliação direcionado para componentes que limitam o desempenho ${ }^{85}$.

Dessa forma, tem-se uma perspectiva global sobre o cliente e sua participação nos contextos de vida para identificar o que é relevante na intervenção, a partir da perspectiva do cliente ${ }^{86}$. Assim, o perfil ocupacional incluirá informações sobre as necessidades do paciente, problemas e preocupações referentes à sua capacidade de desempenho para a participação em ocupações. A análise do desempenho ocupacional utiliza-se da coleta e interpretação de informações para identificar suportes e barreiras e assim detectar possíveis áreas de intervenção ${ }^{3}$.

A obtenção dessas informações pode acontecer através da utilização de escalas padronizadas e validadas para serem utilizadas por terapeutas ocupacionais, para mensurar a efetividade da sua atuação, além de, por meio da prática baseada em evidências, comparar a sua intervenção com a de terapeutas de outras regiões ou outros países ${ }^{87}$. Outro meio de avaliação de grande valia para o processo de reabilitação pós COVID-19 é a observação do paciente executando atividades do dia a dia, a fim de se analisar possíveis comprometimentos na independência e funcionalidade ${ }^{25}$.

O terapeuta ocupacional realiza a avaliação funcional, abrangendo aspectos sensório-motores, 
cognitivos, psicoemocionais e sociais. Com esses pacientes, o atendimento é focado no treino das AVDs, técnicas de conservação de energia, assim como nas atividades significativas, de modo a ampliar a capacidade funcional, participação/interação social e qualidade de vida.

De posse das informações obtidas tanto na aplicação de avaliações padronizadas, quanto na observação do desempenho das AVDs e atividades instrumentais da vida diária (AIVDs) o terapeuta poderá implementar um plano terapêutico personalizado e focado na superação das necessidades individuais. O terapeuta poderá analisar aspectos funcionais (nível de independência e padrão de execução de atividades), aspectos cognitivos e níveis de alerta, avaliação da sensibilidade (superficial, profunda e cortical), avaliação motora (coordenação motora e força muscular), avaliação do ambiente (identificação de barreiras ou facilitadores) e também a avaliação da necessidade de recursos de tecnologia assistiva.

Intervenção: Munidos das informações obtidas no processo de avaliação, o terapeuta poderá planejar a intervenção com foco na ocupação. Dessa forma, a intervenção terá por objetivo desenvolver um plano com metas focadas na ocupação para a restauração da função ocupacional, levando em consideração a evolução do paciente ao longo do processo e, se necessário, fazendo o encaminhamento para outros profissionais

Segundo a literatura, tratamentos que incluem mobilização precoce são capazes de reduzir as complicações decorrentes da internação. Esses estudos reconhecem o terapeuta ocupacional como membro da equipe que planeja e executa os programas de reabilitação ${ }^{88,89}$. Assim, ampliando a qualidade funcional do paciente com a reabilitação pós COVID-19.

Devido aos comprometimentos decorrentes da COVID-19, podem surgir comprometimentos nas ocupações como resultado da internação para tratamento da infecção, por déficits nas habilidades de desempenho ou pela combinação de ambos os fatores. A utilização da ocupação como recurso terapêutico é um fator positivo na melhora funcional do paciente, na ampliação da sua autonomia e na restauração da rotina de atividades, reduzindo, assim, os impactos da internação hospitalar ${ }^{90}$.

Como a fadiga é uma das principais manifestações da COVID-1927, será necessário dar especial atenção às AVDs quanto ao consumo de energia na execução. A utilização de técnicas de conservação de energia, adaptação ambiental e adequação postural são meios eficazes para reduzir a sensação de fadiga ${ }^{91}$.

O terapeuta deve buscar organizar a rotina de atividades, de modo a permitir maior funcionalidade com o menor gasto energético possível, para que o paciente consiga executar seus cuidados de forma independente. A rotina de AVDs deve ser estruturada de modo que o paciente tenha tempo de descanso entre uma atividade e outra. O paciente deve ser orientado quanto à postura mais adequada para permitir a conservação de energia, como cruzar uma perna sobre a outra para possibilitar calçar meias e calçados, por exemplo. Orientase que o paciente mantenha a postura sentada para a realização das AVDs. O ambiente também deverá ser reorganizado para possibilitar que os objetos de uso do paciente sejam de fácil acesso ${ }^{90,92}$.

A reabilitação pós-COVID-19 é desafiadora no sentido que a combinação do processo de hospitalização somado às sequelas resultantes da infecção, impactam diretamente o potencial funcional do paciente e compromete a sua independência. O terapeuta ocupacional deverá ser criterioso ao avaliar e implementar o plano terapêutico, pois é necessário focar não apenas nas limitações que a doença impõe, mas também nas suas relações com a execução das AVDs e participação social do paciente. O processo de reabilitação pós-COVID-19 deverá então ser baseado tanto na combinação de componentes da ocupação (AVDs, AIVDs, sono, educação, trabalho, brincar, lazer e participação social) como também na intervenção em habilidades de desempenho (habilidades motoras, de processo e interação social).

Para atingir tais objetivos, a reabilitação deve implementar medidas para prevenção de alterações nas áreas de ocupação, auxiliando na reestruturação da rotina após a COVID-19. Em função do período de internação, o foco inicial deve ser dado às questões cognitivas do paciente como: orientação tempo e espaço, quadro clínico e dúvidas sobre o processo de hospitalização e reabilitação.

Os componentes de desempenho também possuem um papel especial na reabilitação das sequelas provenientes da infecção pelo vírus SARS-COV-2, em que deverá ser trabalhada a percepção sensorial do paciente e sua relação com a 
função manual (coordenação motora fina, destreza e praxia). Como um meio de estimular a participação da pessoa no seu retorno para a casa é fundamental a identificação de barreiras (arquitetônicas, sociais e atitudinais) que possam impactar a funcionalidade.

Como meio de permitir e ampliar a participação nas ocupações nesse período da reabilitação, o terapeuta ocupacional poderá avaliar, indicar e treinar o uso de recursos de tecnologia assistiva (órteses e dispositivos para ampliar/favorecer função e independência funcional).

Toda a intervenção aplicada nesse contexto tem como objetivo final permitir a realização das AVDs e AIVDs de forma mais independente possível.

Assim a reabilitação visa promover motivação frente ao tratamento e participação social, orientar e adaptar para o retorno à atividade laboral, e também orientar familiares e cuidadores sobre o gradual retorno das habilidades físicas e cognitivas do paciente. Ainda não se sabe qual será o real impacto físico futuro causado pelo vírus SARS-COV-2 e suas complicações no desempenho ocupacional dos sujeitos infectados. Pessoas que se recuperam da COVID-19 podem apresentar, a longo prazo, sintomas diversos e evoluir para disfunções e incapacidades.

\section{Cuidados paliativos}

Em 2020, a Associação Internacional para Hospice e Cuidados Paliativos (IAHPC) publicou sua versão brasileira da definição de Cuidados Paliativos como resultado do Global Project - Consensus Based Palliative Care Definition:

Os Cuidados Paliativos são cuidados holísticos ativos, ofertados a pessoas de todas as idades que se encontram em intenso sofrimento relacionados à sua saúde, proveniente de doença grave, especialmente aquelas que estão no final da vida. O objetivo dos Cuidados Paliativos é, portanto, melhorar a qualidade de vida dos pacientes, de suas famílias e de seus cuidadores ${ }^{93}$.

Essa nova definição enfatiza que o sofrimento é um dos pontos centrais do cuidado paliativo, que o cuidado paliativo é uma abordagem mais centrada na pessoa e em suas necessidades, não na doença nem no prognóstico ou estágio da doença, e que é aplicável em todos os contextos e níveis de atenção, sejam cuidados gerais ou especializados. Embora a integração precoce seja preconizada nos protocolos de tratamento para adultos, idosos e crianças, seja no câncer ou em outras condições clínicas, para melhorar o controle dos sintomas e a qualidade de vida, há uma grande variação nas definições de como e quando os cuidados paliativos devem ser implementados no continuum do cuidado ${ }^{94}$

Ainda que esta pandemia seja uma crise de cuidados agudos de duração desconhecida, dezenas de milhares de pessoas podem morrer, principalmente os pacientes em cuidados paliativos, que são aqueles que correm maior risco, como as pessoas idosas, frágeis ou com doenças crônicas graves e avançadas.

A COVID-19 vem destacando a importância e necessidade de que o cuidado paliativo seja compreendido também como um componente essencial na resposta a epidemias e emergências humanitárias $^{95}$. Seu papel é manter o cuidado, mesmo quando o sistema de saúde, os trabalhadores de saúde e os pacientes estejam exauridos. É preciso gerenciar a dor e os sintomas, manejar o sofrimento, garantir conforto na morte e apoiar as famílias e os prestadores de cuidados.

Em 19 de maio de 2020, a $73^{a}$ Assembleia Mundial da Saúde estimulou os Estados membros a incluírem os cuidados paliativos em sua resposta à COVID-19. A Organização Mundial da Saúde (OMS) incluiu no seu "Guia Interino para Gerenciamento Clínico da COVID-19" a informação de que os cuidados paliativos devem ser oferecidos por todos aqueles que cuidam de pessoas afetadas pelo COVID-19, incluindo o alívio de sintomas e o apoio social ${ }^{96}$.

As necessidades de coordenar cuidados e de tomar decisões difíceis relativas aos cuidados de final de vida podem exigir a intervenção de profissionais de cuidados paliativos nas condições em que as comunicações são dificultadas pela ausência de informações claras e quando os próprios profissionais estão sobrecarregados e em risco, com sinais de sofrimento, tristeza e frustração.

Se os recursos de atenção à saúde estiverem esgotados pela sobrecarga do sistema, é possível que pessoas que estejam em cuidados de final de vida não sejam priorizadas para o atendimento em UTI, pela indisponibilidade de ventiladores e de leitos para todos, o que evidencia 
ainda mais o valor dos cuidados paliativos são imprescindíveis para o atendimento a essa população durante esta pandemia.

De acordo com a Declaração e Apelo à Ação em Cuidados Paliativos \& COVID-19 da Fundação Elisabeth Kübler-Ross, os sistemas de saúde devem ${ }^{97}$ :

- aceitar a responsabilidade ética e moral de cuidar do sofrimento relacionado ao COVID-19, integrando os cuidados paliativos, inclusive para grupos vulneráveis;

- fornecer capacitação em cuidados paliativos aos profissionais de saúde envolvidos nos cuidados a pessoas com COVID-19;

- garantir o acesso a medicamentos essenciais e controlados para poder oferecer cuidados paliativos às pessoas com COVID-19;

- $\quad$ oferecer assistência a pessoas enlutadas.

Apesar dos cuidados oferecidos, muitas pessoas têm morrido como consequência da pandemia da COVID-19. Segundo Bye (1998), no seu artigo "When clients are dying: occupational therapists' perspectives":
As pessoas com doença terminal não se adaptam [a uma abordagem reabilitativa de terapia ocupacional] porque perdem papéis e eventualmente se afastam da sociedade... Pessoas em estado terminal sofrem deterioração progressiva em termos de independência funcional, muitas vezes requerem uma parcela significativa de cuidados de outras pessoas e suas vidas não continuarão a ser produtivas. Elas morrem ${ }^{98}$.

Quando pacientes com COVID-19 evoluem para a finitude da vida, podem passar por diferentes etapas e construir mecanismos de enfrentamento do processo de morte e morrer. Em 1969, a Dra. Elisabeth Kübler-Ross descreveu uma série de reações emocionais como estágios ou mecanismos de enfrentamento para mudança, perda e/ou choque, que ela identificou como os " 5 Estágios da Morte ${ }^{\mathrm{TM}}$ ", também conhecidos como os " 5 estágios do processo do morrer" ${ }^{\mathrm{TM} \text { " ou " } 5}$ estágios da perda ${ }^{\mathrm{TM}}$ ". Mais recentemente, os 5 estágios foram ampliados para 7 estágios (não sequenciais, nem lineares), entendidos como uma "Curva da Mudança Kübler-Ross ${ }^{\mathrm{TM}}$ ", conforme Figura 2, a seguir.

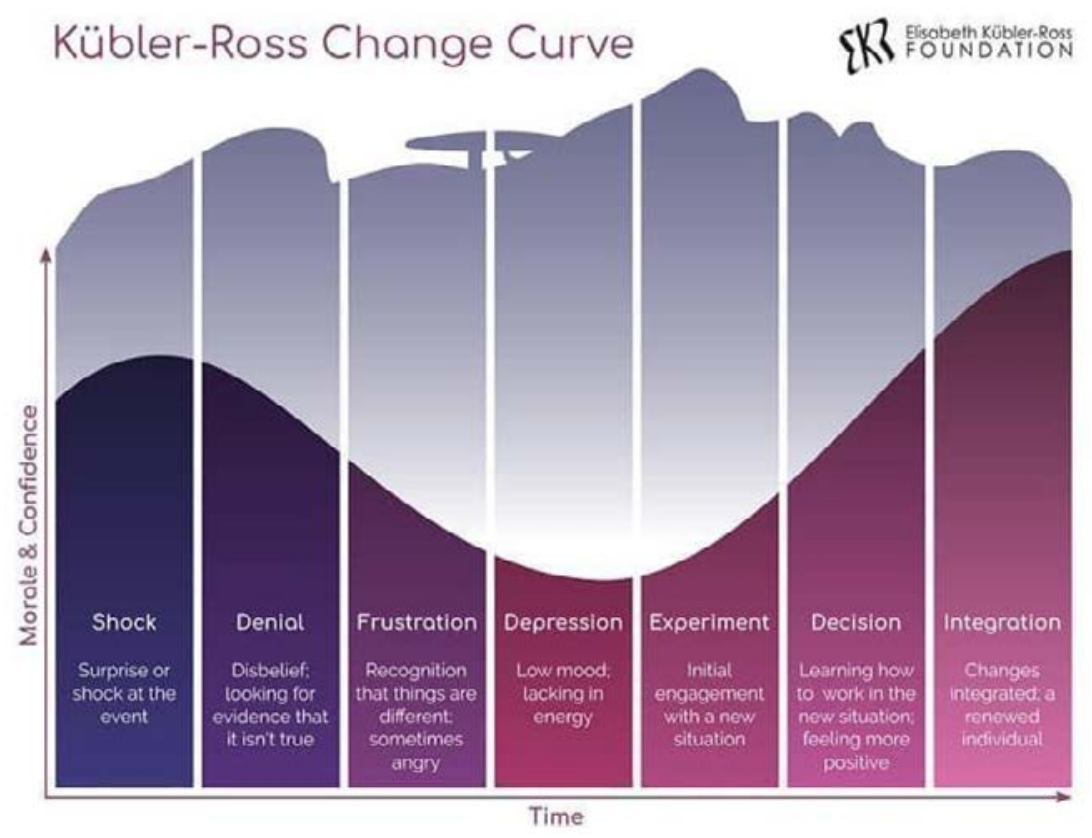

Figura 2: Curva da Mudança Kübler-Ross ${ }^{\text {TM", }}$ Copyrighted \& Trademarked by: Elisabeth Kübler-Ross Family Limited Partnership99. 
De acordo com a Figura 2:

- Shock - Choque: surpresa ou choque (ao receber o diagnóstico e/ou prognóstico);

- Denial-Negação: descrença. Procurando evidências de que não é verdade;

- Frustration - Frustração: reconhecimento, às vezes com raiva, de que as coisas são diferentes do que esperava;

- Depression - Depressão: humor baixo e falta de energia;

- Experiment-Experiência: Engajamento inicial com uma nova situação;

- Decision - Decisão: Aprender a trabalhar na nova situação; sentindo-se mais positivo;

- Integration - Integração - mudanças integradas; uma integração renovada.

Cada pessoa tem seu próprio modo de se aproximar da morte e de viver seu luto. Seus problemas, ansiedades, sentimentos e anseios, requerem uma intervenção singular. São desafios no diagnóstico e no tratamento a avaliação do sofrimento emocional e espiritual /existencial, que comumente são apresentados pelas pessoas em cuidados paliativos. Por isso a equipe deve manter atenção a esses sintomas, buscando melhorar os mecanismos de enfrentamento desses pacientes e manejá-los adequadamente para que não levem a consequências graves, como depressão, desesperança e diminuição da função cognitiva, além de interferir no processo de tratamento ${ }^{100}$.

Além de dor e de sintomas de difícil controle, pessoas em cuidados paliativos costumam sofrer desconfortos psicossociais e espirituais, como dificuldades no relacionamento com os familiares, dificuldades de adaptação à doença, de adesão ao tratamento e de aceitação da possibilidade da morte. Ocorrem medos e dúvidas existenciais, questionamentos espirituais, perda do sentido da vida e da fé ${ }^{101}$.

Os temas da espiritualidade e do cuidado espiritual estão ganhando cada vez mais atenção na saúde em geral, para a melhoria da assistência ao paciente e a seus familiares e cuidadores. $O$ bem-estar espiritual é extremamente relevante na qualidade de vida de todos. Porém, com a progressão da doença, os pacientes costumam enfrentar o declínio clínico-funcional decorrente da doença e a proximidade da morte, associados a aflições existenciais e sofrimentos espirituais, que oscilam no decorrer do tratamento ${ }^{102}$.

Sofrimento espiritual e crises espirituais ocorrem quando os indivíduos são incapazes de encontrar fontes de significado, esperança, amor, paz, conforto, força e conexão na vida ou quando ocorre um conflito entre suas crenças e o que está acontecendo em sua vida. Esta aflição pode ter um efeito prejudicial na saúde física e mental. A doença e a morte iminente podem muitas vezes desencadear sofrimento espiritual em pacientes e familiares ${ }^{103}$.

Quando o sofrimento espiritual não é identificado, o plano terapêutico possivelmente será malsucedido. Segundo Koenig et al (2001) ${ }^{104}$, a crença em aspectos espirituais pode mobilizar iniciativas positivas para melhorar a qualidade de vida da pessoa adoecida. Pacientes com crenças religiosas reconfortantes costumam sentir-se menos "despreparados" e "desesperançosos" no enfrentamento do adoecimento do que aqueles que não têm crenças ou valores religiosos/ espirituais. Manter o sentido da vida e cultivar a espiritualidade é um grande desafio da vida, principalmente frente à possibilidade da morte.

As diferentes práticas em cuidados paliativos estão direcionadas à busca do maior conforto, dignidade, qualidade de vida, manutenção e/ou resgate do domínio sobre a própria vida, de forma mais ativa e participativa e com a redução e/ou eliminação dos processos de exclusão social ${ }^{105}$.

Neste sentido, a reabilitação paliativa (palliative rehabilitation) é um componente integral central da filosofia e da oferta de serviços de cuidados paliativos e vem sendo cada vez mais reconhecida pelas políticas e diretrizes internacionais. Tratase de uma modalidade de atendimento interprofissional baseada no modelo holístico de cuidados paliativos; no Reino Unido, é oferecida principalmente por quatro profissionais de saúde: terapeutas ocupacionais, fisioterapeutas, fonoaudiólogos e nutricionistas (que são denominados Allied Health Professionals pelo National Health Service - NHS do Reino Unido).

O objetivo da reabilitação paliativa é otimizar o cuidado às pessoas que apresentam doenças 
limitadoras da vida, de forma que possam ter conforto e bem-estar e que possam viver de forma tão autônoma, independente e funcional quanto for possível, ainda que com limitações e incapacidades decorrentes do avanço da doença. É uma abordagem que fornece um sistema de apoio ativo para ajudar as pessoas adoecidas a se adaptar às suas condições de vida com dignidade e a enfrentar construtivamente as perdas resultantes da deterioração da saúde ${ }^{106}$.

Através da reabilitação paliativa, os terapeutas ocupacionais oferecem oportunidades para que os pacientes e cuidadores participem de ocupações e papéis ocupacionais significativos para eles, mantendo o prazer da realização dessas ocupações na vida cotidiana, ao mesmo tempo em que se preparam para a morte.

O terapeuta ocupacional inserido na equipe multidisciplinar de Cuidados Paliativos tem como objetivo aliviar o sofrimento, minimizar o impacto da alteração da rotina, contribuir no controle de sintomas por estratégias não farmacológicas, preservar/resgatar as habilidades de desempenho ocupacional, facilitar a comunicação assertiva e proporcionar acolhimento e orientações à família, ações pautadas no perfil ocupacional do paciente e no seu direito à autonomia, independência e qualidade de vida, nos diversos níveis de atenção à saúde ${ }^{107}$.

Há necessidade de cuidar também daqueles que ficam após a morte da pessoa adoecida. O luto é um dos eventos que mudam a vida e as pessoas enlutadas devem ser ajudadas a pensar sobre e enfrentar sua tristeza, compreendendo que as pessoas amadas não foram perdidas com a morte, porque elas continuarão como parte da vida de quem ficou. A comunicação com os familiares e cuidadores deve ser sensível e empática, estimulando a expressão de suas emoções e sentimentos, pois não existe um modo certo ou errado de viver o luto e de lidar a morte ${ }^{108,109}$.

Por fim, cuidado paliativo é um direito humano, um caminho mais humanizado e sem obstinação terapêutica, conferindo acolhimento e significado à existência ${ }^{110}$.

\section{Abordagens e recursos terapêutico-ocupacionais}

\section{Manejo de dor e de sintomas}

\section{- Dor}

Segundo a Associação Internacional de Estudos da Dor (IASP), a dor é "uma experiência sensitiva e emocional desagradável, associada, ou semelhante àquela associada, a uma lesão tecidual real ou potencial"111. Essa nova definição revisada foi publicada recentemente e veio acompanhada de seis notas importantes sobre a dor:

- a dor é sempre uma experiência pessoal que é influenciada, em graus variáveis, por fatores biológicos, psicológicos e sociais;

- dor e nocicepção são fenômenos diferentes. A dor não pode ser determinada exclusivamente pela atividade dos neurônios sensitivos;

- $\quad$ através de suas experiências de vida, as pessoas aprendem o conceito de dor;

- o relato de uma pessoa sobre uma experiência de dor deve ser respeitado;

- embora a dor geralmente cumpra um papel adaptativo, ela pode ter efeitos adversos na função e no bem-estar social e psicológico;

- a descrição verbal é apenas um dos vários comportamentos para expressar a dor; a incapacidade de comunicação não invalida a possibilidade de um ser humano ou um animal sentir dor. ${ }^{(*)}$

Na COVID-19 podem ocorrer manifestações de dor e sintomas como febre, cansaço, perda de olfato ou paladar e em casos mais graves, dificuldade para respirar. Este último, principalmente na população de risco, pode se agravar e se tornar uma ameaça à vida, fazendo com que o paciente necessite de isolamento hospitalar e utilização de medidas invasivas para o tratamento. Como todo diagnóstico, este pode vir acompanhado de dor e é importante que os profissionais se envolvam na busca de alívio e manejo, com medidas farmacológicas e/ou não-farmacológicas. 
Ainda não foram identificados estudos referentes a quadros de dor em pacientes internados com COVID 19, apenas relatos de dor torácica, dor no peito e dor de garganta apresentados por alguns pacientes ${ }^{112,113}$. Porém, sabe-se que a dor pode se apresentar de diversas formas, seja pelas características agudas da enfermidade ou por medo do desconhecido, desorientação, angústias e solidão. A dor pode ocasionar alterações no desempenho ocupacional da pessoa incluindo incapacidades para realizar atividades e inaptidão para exercer seus papéis ocupacionais. Por isso, deve-se manter um olhar voltado aos sintomas físicos, emocionais, sociais e espirituais que interferem na dor e na qualidade de vida de cada paciente.

Estudos demonstraram que emoções como medo, raiva e tristeza diminuem o limiar da dor e o nível de preocupações adicionais e/ou outros sintomas além da dor física podem estar presente na maioria dos pacientes em unidades de internação, ocasionando um nível mais elevado de sentimentos deprimidos, ansiedade familiar e preocupações com questões práticas do cotidiano ${ }^{114,115}$.

Em um cenário totalmente novo, como é a atual situação da pandemia, deve-se refletir no quanto esse contexto interfere na vida do paciente em seus diversos aspectos, podemos correlacionar com o conceito da dor total ${ }^{116}$, pois, apesar da dor na COVID-19 ser pontual, diante do novo, do desconhecido, o paciente pode apresentar dores emocionais, como angústias, ansiedade, medo da piora dos sintomas, do risco de agravamento e necessidade de medidas invasivas, como intubação, internação em UTI, garantia de tratamento e receio diante da cura, visto que ainda não existe um tratamento específico. A dor social advinda do afastamento de sua família, amigos, do contexto em que está inserido, preocupações adicionais relacionadas a seus papéis ocupacionais, como provedor do lar, entre outras. Dor espiritual relacionada ao sentido da vida, a estar diante de situações de vida e morte, com incertezas, questionamentos e às vezes culpa.

O terapeuta ocupacional possui conhecimento, habilidade e expertise para avaliar como a dor interfere nos domínios físico, social e espiritual do paciente e entender toda complexidade da sua influência na vida do indivíduo ${ }^{117}$. Através dessa avaliação, o terapeuta ocupacional oferece ferramentas para o gerenciamento da dor na vida cotidiana, com intervenções como modificação de atividades de trabalho e nas AVDs ${ }^{118}$.

Portanto, o terapeuta ocupacional pode, em várias interfaces, auxiliar o paciente com dor neste cenário específico, buscando ressignificar as ações e atuar na disfunção ocupacional e em questões biopsicossociais, valorizando o paciente como um todo, respeitando sua individualidade e compreendendo o contexto em que está inserido, considerando que os impactos físico, psicoemocional, cognitivo e social das limitações funcionais são fatores relevantes diante do manejo da dor. Assim, deve-se buscar junto ao paciente, um envolvimento significativo e prazeroso de acordo com sua realidade atual, voltado para uma significativa redução da dor.

Alguns objetivos e ações que o terapeuta ocupacional pode atuar junto ao paciente nesse contexto incluem:

- possibilitar medidas não-farmacológicas para prevenção e controle da dor e outros sintomas;

- utilizar as técnicas de conservação de energia;

- $\quad$ prescrever, desenvolver e promover o uso de adaptações para AVDs, buscando manter o desempenho ocupacional;

- $\quad$ prescrever, desenvolver e promover o uso de órteses e adaptações, promovendo conforto no leito;

- prescrever, desenvolver e promover o uso de comunicação alternativa, favorecendo a comunicação do paciente, seus desejos e vontades, bem como angústias e incertezas;

- capacitar o paciente para alcançar um nível de desempenho satisfatório nas áreas de desempenho para apoiar a recuperação, a saúde, o bem estar e a participação social;

- promover o autogerenciamento da dor, conscientização postural e a reorganização de atividades;

- realizar o acolhimento a familiares e cuidadores;

- $\quad$ estimular e favorecer o uso de técnicas de distração e relaxamento;

- elaborar kits e guias de orientações para atividades/rotina domiciliar. 


\section{- Delirium}

O delirium é um estado confusional agudo marcado por desatenção e disfunção cognitiva global, sendo multifatorial e que se desenvolve devido a interações entre fatores de risco e insultos nocivos ${ }^{119}$.

O delirium pode estar presente dentre os quadros neurológicos associados à COVID-19, pois é um problema frequente do paciente em estado crítico, associado com internações mais prolongadas, tanto no contexto da UTI, quanto na internação hospitalar anterior ou posterior à UTI, podendo levar a um comprometimento da funcionalidade e do funcionamento psicossocial, da qualidade de vida e da redução da sobrevida 25 .

O terapeuta ocupacional, como membro da equipe interdisciplinar, no tratamento da COVID-19, atua os cuidados agudos na reabilitação, por meio de abordagens voltadas à prevenção, detecção e monitoramento de delirium para prevenir complicações e reduzir sequelas funcionais, cognitivas e emocionais. Os possíveis recursos terapêuticos a serem utilizados são descritos a seguir ${ }^{82,119}$ :

\section{Cognição / Orientação}

- $\quad$ utilização de atividades de estimulação cognitiva;

- $\quad$ orientações verbais ou escrita em quadros, sobre data, hora, local e identidade de membros da equipe e familiares;

- orientações claras e frequentes sobre cada intervenção, atendimento e programação diária dentro da rotina hospitalar;

- orientações sobre comunicação, mediando a comunicação entre paciente, familiares e equipe;

- estimulação ambiental adequada, como o controle de iluminação e de temperatura, para facilitar a segurança do paciente.

\section{Mobilidade precoce}

- $\quad$ estimulação de deambulação ou exercícios ativos de amplitude de movimento.

\section{Audição}

- $\quad$ utilização de dispositivos amplificadores portáteis e técnicas especiais de comunicação, com reforço diário;
- utilização de comunicação alternativa quando a comunicação verbal for limitada.

Preservação do ciclo sono-vigília

- realização de técnicas de relaxamento, música e massagem;

- utilização de estratégias de redução de ruído em toda a unidade e ajustes para permitir sono mais ininterrupto possível.

Visão

- aplicação de recursos visuais (óculos, lentes de aumento) e equipamentos adaptativos quando necessário.

\section{- Dispneia e fadiga}

Durante o período de internação hospitalar, a terapia ocupacional tem como uns dos objetivos atuar na reabilitação pulmonar ${ }^{120}$ e no manejo de sintomas como a dispneia e a fadiga.

Muitas condições preexistentes, como doenças cardíacas ou pulmonares, causam dispneia, sendo esse sintoma também decorrente da COVID-19. A dispneia se apresenta na forma de uma respiração difícil e desconfortável, podendo afetar o desempenho ocupacional e a vida das pessoas acometidas por esse sintoma. Além disso, pode se apresentar de forma muito assustadora e angustiante, mesmo em casos mais leves, podendo ser agravada por medos relacionados ao novo coronavírus ${ }^{121}$.

são sinais comuns a pacientes com dispneia e fadiga:

- ficar sem fôlego após um esforço mínimo;

- não ser capaz de realizar suas tarefas, hobbies ou interesses normais;

- presença de cansaço ou vir a apresentar cansaço após fazer pouca ou nenhuma atividade;

- $\quad$ ansiedade e possivelmente ataques de pânico;

- falta de concentração;

- irritação ou tristeza.

A dispneia impacta no desempenho das ocupações do cotidiano. Em casos críticos o paciente recebe cuidados intensivos na UTI. Após a estabilização do quadro clínico, o paciente é transferido para a enfermaria para a continuação dos cuidados 
e do planejamento da alta hospitalar e retorno às atividades em rotina extra-hospitalar.

O foco principal do terapeuta ocupacional no tratamento da dispneia é o gerenciamento do alívio dos sintomas por meio de abordagens não farmacológicas, visando a melhor participação da pessoa em suas ocupações cotidianas, a melhora da qualidade de vida e o melhor posicionamento para maximizar o funcionamento respiratório.

Na maioria das pessoas que apresenta dispneia em decorrência da COVID-19, a fadiga é também vista com frequência. A fadiga afeta a qualidade de vida devido à sensação de cansaço que a pessoa apresenta em participar plenamente dos papéis, relacionamentos e atividades que tornam sua vida significativa ${ }^{122}$. Sinais comuns:

- dificuldades para realizar as tarefas de autocuidado, como pentear o cabelo e se vestir;

- $\quad$ sensação de estar sem energia ou força;

- dificuldade de concentração e de memória;

- falta de desejo sexual;

- apresentar tonturas;

- alterações de sono e descanso;

- dificuldades para pensar, falar e tomar decisões;

- alteração no estado de humor, como humor mais rebaixado ou mais emocional que o habitual.

Aprender a controlar alguns desses sintomas angustiantes pode torná-los mais suportáveis. Existem muitas abordagens que o terapeuta ocupacional pode utilizar no manejo deste sintoma por meio de técnicas de respiração, relaxamento, posicionamento e orientações ${ }^{121}$. Serão apresentadas, a seguir, algumas intervenções que podem ajudar o paciente a encontrar maneiras de conservar energia ao realizar suas tarefas diárias.

- exercícios de respiração relaxada, de respiração abdominal (respiração diafragmática) e de respiração freno labial (lábios franzidos);

- técnica de respiração quadrado ou retângulo;

- técnicas de relaxamento muscular progressivo;

- usar a técnica de calming hand para gerenciar ataques de pânico;

- mindfulness;

- meditação;

- $\quad$ pacing de atividades;

- manutenção do paciente ao lado de janelas abertas;

- orientações para a diminuição da sensação de dispneia, por meio de indicação ao paciente que refresque o rosto, especialmente ao redor do nariz, com um pano ou algo que possa molhar e posicionar no nariz e nas bochechas superiores do rosto. $O$ uso de ventiladores não está sendo recomendado durante o surto de coronavírus devido ao risco de propagação da infecção;

- $\quad$ orientação ao paciente sobre posicionamento em poltronas e no leito, conforme apresentado nas figuras abaixo:
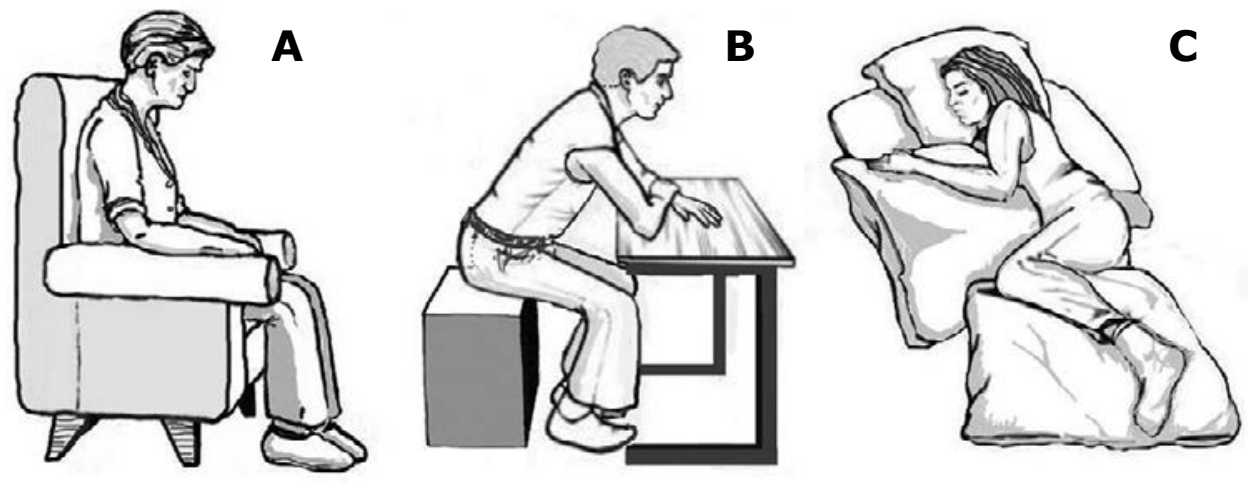

Figuras 3-5: Sugestões de posicionamentos para manejo de $\operatorname{sintomas}^{123}$. 
A. sentar-se em uma poltrona confortável, com os dois braços apoiados nos braços ou almofadas da cadeira, deixar os ombros caírem e relaxem, com as solas dos pés no chão;

B. sentar-se em uma cadeira e deixar o corpo cair para a frente, descansando os dois braços sobre uma mesa ou sobre os joelhos para apoiá-los;

C. deitar-se de lado, apoiando-se em travesseiros na parte superior do corpo. Colocar o travesseiro superior no pescoço para apoiar a cabeça, descansando o braço em um travesseiro, colocado na frente do peito, e a perna em outro. Relaxar os punhos, dedos e a mandíbula.

Assim, durante e após a COVID-19, é provável que o paciente tenha menos energia e se sinta cansado. Uma tarefa simples do dia a dia pode tornar-se árdua e cansativa ao ser realizada, como trocar as roupas e os sapatos ou realizar as tarefas domésticas e de trabalho. Por vezes, pequenas alterações na forma de realizar suas ocupações podem favorecer que a pessoa tenha mais energia ao longo do dia e melhor qualidade de vida ${ }^{124}$.

\section{Conservação de energia e pacing de atividades}

Técnica de conservação de energia: é uma técnica utilizada para o desempenho ocupacional do cotidiano com menor gasto energético. É poupar esforços na realização das ocupações através de estratégias que visam reduzir energia, estresse e dor. 125

São princípios de conservação de energia:

- planejar e organizar suas ocupações;

- estabelecer prioridades;

- evitar a pressa;

- eliminar tarefas e movimentos desnecessários;

- utilizar dispositivos de tecnologia assistiva para reduzir o esforço;

- $\quad$ programar períodos de descanso entre uma atividade e outra ou durante uma atividade longa;

- promover um ambiente de trabalho adequado e organizado (luz, ventilação, mobiliário).

Pacing de atividades: tem como objetivo priorizar e planejar a execução das ocupações de forma a reduzir o esforço, para que se mantenha um nível equilibrado e constante entre sua realização e os períodos de descanso, de forma a não causar algum dano ou desconforto ao paciente, aumentando a tolerância durante o tempo das ocupações ${ }^{126}$.

As técnicas de conservação de energia e pacing de atividades podem reduzir a dor e o estresse, aumentar a independência do paciente, compensar limitações funcionais, aumentar a tolerância na execução das atividades, entre outros objetivos. Dentre as estratégias com pacientes com COVID-19 podem ser citadas:

- a organização da rotina ocupacional dos pacientes, considerando a sua condição clínica, as atividades necessárias, as intervenções a que é submetido por outros profissionais, o tempo para o desempenho e os níveis de exigência de cada uma, analisando também o intervalo de descanso necessário;

- a simplificação das ocupações, adaptando-as, como uso de engrossadores para o talher e a escova de dente, assim como o uso de coxins, rolos e travesseiros para o posicionamento no leito, o que favorece o desempenho das atividades de alimentação e higiene oral;

- orientação quanto às posturas mais adequadas para a realização de cada uma das ocupações, priorizando as posições com menor gasto energético? ${ }^{7}$.

Há também o conjunto de técnicas chamado de "5 Ps" 127:

1- Planejamento:

- planejar a forma de utilização dos níveis de energia com eficiência;

- planejar a realização das atividades e descansar, fazendo uma pausa antes de se cansar;

- trabalhar com metas e expectativas realistas a respeito do que de fato possa ser alcançado no dia;

- escolher a melhor hora do dia para cada atividade;

- planejar e dividir as tarefas maiores em estágios menores. 


\section{2- Priorização}

- identificar o que é realmente importante;

- fazer uma lista de tarefas para a semana / dia;

- perguntar: Precisa ser feito hoje? Tudo precisa ser feito agora? Precisa ser feito pelo próprio paciente ou a tarefa pode ser delegada a outra pessoa? O paciente quer realmente fazer essas atividades?

\section{3- Pacing de atividades}

- organizar e aproveitar de forma mais adequada o tempo, espaçando as atividades ao longo do dia;

- equilibrar as tarefas mais pesadas e leves ao longo do dia;

- desacelerar, não apressar e não exagerar quando estiver fazendo atividades, respeitando os limites do corpo;

- programar períodos de descanso durante as atividades.

\section{4- Postura / Posicionamento}

- evitar "desperdício de energia" mantendo uma boa postura;

- realizar atividades em sedestação ao invés de ficar em ortostatismo;

- usar equipamentos e tecnologias assistivas para poupar energia;

- organizar os itens usados com frequência de fácil alcance, considerando a posição / localização / altura das coisas dentro do ambiente (hospitalar ou domiciliar).

\section{5- Permissão}

- permitir dias ruins, mas não tentar colocar todas as atividades para fazer nos dias bons;

- mudar a forma de falar: ao invés de "eu devo", mudar para "eu desejo" e "eu escolho";

- fazer uma pausa / permitir mudanças;

- estimular que o paciente seja gentil consigo mesmo - permitir pedir ajuda.

A utilização de técnicas de respiração e relaxamento pode ser uma parte importante da conservação de energia para auxiliar no manejo da ansiedade na melhora. da qualidade de vida e no manejo de dor e desconforto ${ }^{128}$. Neste sentido, o paciente deve ser estimulado a reservar um tempo para si mesmo, estimular a realização de atividades prazerosas, como escutar música, ler, assistir televisão, dentre outras ocupações significativas.

\section{Tecnologia Assistiva e Tecnologia de Comunicação Alternativa e Ampliada}

A tecnologia assistiva (TA) é "o ramo da ciência que se envolve com a pesquisa, desenvolvimento e aplicação de equipamentos ou procedimentos que aumentam ou restauram a função humana"126. Tem caráter interdisciplinar e abrange recursos, serviços, estratégias e técnicas com o objetivo de proporcionar melhor qualidade de vida aos indivíduos com perdas funcionais transitórias ou permanentes.

O terapeuta ocupacional tem um papel central no desenvolvimento da capacidade funcional e do desempenho ocupacional, com independência nas atividades de vida diária, no controle do ambiente em que vive, entre outras. Para isso, o terapeuta ocupacional promove o uso de tecnologia assistiva na realização de ocupações específicas em diferentes contextos. Os recursos de tecnologia assistiva estão presentes nas ações intra e extra-hospitalares realizadas por terapeutas ocupacionais, de modo a:

- favorecer o alívio e o controle de sintomas e o apoio psicossocial e espiritual com ações centradas no paciente e não na doença;

- promover o máximo de independência e/ou autonomia no desempenho ocupacional;

- confeccionar coxins para promover a posição prona, buscando a melhora do quadro respiratório e de posicionamento com a intenção de evitar possíveis contraturas;

- $\quad$ promover a independência e prevenir dor e deformidades, por meio da prescrição de cadeiras de rodas, equipamentos adaptativos e órteses;

- adaptar utensílios para AVDs e AIVDs para promover a capacidade funcional; 
- $\quad$ prescrever e possibilitar o uso de dispositivos auxiliares de locomoção, como cadeiras de rodas;

- prescrever e possibilitar o uso de recursos de comunicação alternativa ou ampliada.

Tecnologia de Comunicação Alternativa e Ampliada (TCAA) - A comunicação é uma necessidade básica e um fator essencial da condição humana que torna possível o existir e interagir. Pacientes acometidos pela COVID-19 podem necessitar de cuidados intensivos. Alguns relatórios iniciais mostram que até $5 \%$ dos pacientes infectados podem requerer cuidados em CTI.

Em alguns casos, o paciente pode ficar impossibilitado de se comunicar verbalmente e, quando a comunicação verbal não for possível, torna-se indispensável o uso de recursos terapêuticos e/ou assistivos de comunicação para auxiliar a pessoa no processo de comunicação, visando beneficiar sua interação com o meio e a manifestação de desejos, vontades, angústias e outras preocupações advindas do tratamento.

O terapeuta ocupacional pode auxiliar nesse processo através do uso de pranchas de alfabeto ou símbolos pictográficos ou sistemas mais sofisticados, como comunicadores de voz, computadores e tablets ${ }^{76}$. Esses sistemas de comunicação podem ser auxiliares ou suplementares, variando de acordo com a necessidade de cada paciente ${ }^{129}$. (Figura 6)

O uso de sistemas ou recursos alternativos para a comunicação varia de acordo com cada pessoa e permite que os pacientes manifestem suas escolhas, de acordo com suas necessidades e desejos.

\section{COMO ESTOU ME SENTINDO}

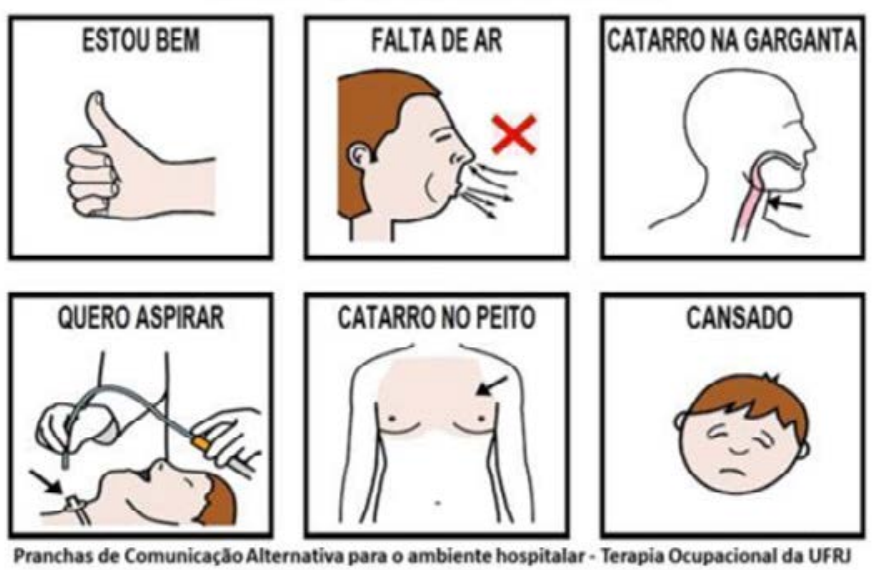

Figura 6: Modelo prancha de comunicação com símbolos relacionados à utilização da ventilação mecânica, processo de desmame e extubação ${ }^{130}$.

\section{Telessaúde e visita virtual}

$O$ advento das novas tecnologias de informação e comunicação vem modificando a lógica da atenção em saúde, especialmente no que diz respeito à superação de barreiras geográficas e à conexão à distância com usuários e profissionais. Elas possibilitam melhorar as atividades de educação, de planejamento da logística de saúde, de regulação da teleassistência e de implementação de métodos para proporcionar atividades multi-institucionais, mesmo que em condições de distanciamento social, como acontece durante a pandemia da COVID-19131-134.

- Telessaúde refere-se ao uso de informações eletrônicas e tecnologias de telecomunicações para prestação de serviços relacionados com a saúde à distância. Pode ser utilizada para avaliação, intervenção, monitorização, supervisão e consultoria (entre 
o terapeuta, cliente, e/ou a instituição prestadora de cuidados de saúde quando qualquer um esteja distante do outro), conforme seja permitido pelos regulamentos jurisdicionais, institucionais e profissionais e pelas políticas que regem a prática da terapia ocupacional.

- Teleconferência/ videoconferência é um ambiente de comunicação síncrona permite interatividade à distância ${ }^{135}$. Com a redução nos custos de infraestrutura, as teleconferências/videoconferências passaram a ser utilizadas para fins educativos. Na Teleducação, trata-se de uma modalidade de educação à distância, utilizando-se softwares específicos que permitem relacionamentos virtuais dentro de ambientes físicos informatizados, que tem sido utilizada para a formação de recursos humanos e para a educação continuada em saúde. Assim, as videoconferências em terapia ocupacional incluem também prevenção, educação continuada, orientação e facilitação do desempenho ocupacional, promoção de saúde, bem-estar e qualidade de vida131,132.

- Telemedicina/ Teleassistência é a oferta de serviços de atenção à saúde por profissionais de saúde, nas situações em que a distância é um fator crítico para a troca de informações necessárias para o diagnóstico, tratamento e prevenção de doenças, para pesquisas e avaliação e também para a educação continuada dos provedores e profissionais de saúde, com o objetivo maior de promover a melhoria da saúde dos indivíduos e das comunidades ${ }^{136}$. São elementos inerentes à telemedicina/ telessaúde o oferecimento de suporte clínico e a superação de barreiras geográficas, conectando usuários à distância e melhorando a atenção à saúde prestada à população ${ }^{137-140}$.

- Telereabilitação é um modelo de prestação de serviços via tecnologia de telecomunicação interativa, bastante funcional nas condições de distanciamento social devido à pandemia de COVID-19; possibilita o oferecimento de serviços de prevenção, diagnóstico e de reabilitação para pacientes, familiares, cuidadores ou a consultoria para equipes, incluindo a implementação de tecnologias assistivas e adaptativas, dentre outros objetivos ${ }^{131}$.

Os serviços de terapia ocupacional via telessaúde ou telereabilitação devem ser apropriados aos indivíduos, grupos ou culturas a que são prestados; contextualizados com as ocupações e interesses dos clientes; e obrigados a empregar mecanismos que assegurem a confidencialidade dos dados síncronos armazenados, relativos ao cliente, de acordo com os regulamentos jurisdicionais, institucionais e profissionais e com as políticas que regem a prática da terapia ocupacional.

Porém, ainda existem obstáculos em relação ao fornecimento de terapia ocupacional via telessaúde, desde questões éticas em relação à privacidade e segurança das informações, até dificuldades das populações atendidas em relação à utilização de recursos tecnológicos. A telessaúde não deve ser utilizada como forma de evitar serviços presenciais quando estes são indicados para as necessidades específicas do cliente, não devendo também ser utilizada como forma do terapeuta evitar contacto com o cliente com base em fatores de discriminação.

A telessaúde pode ser um modelo de prestação de serviço para a terapia ocupacional em tempos de COVID-19 e pode melhorar e ampliar o acesso a ela. Segundo a Associação Americana de Terapeutas Ocupacionais, esses profissionais podem utilizar a telessaúde para continuar fornecendo terapia ocupacional durante esse período de necessário distanciamento social, de forma a mitigar a transmissão do vírus, principalmente na atenção a populações mais vulneráveis ${ }^{141}$.

Visita virtual - Com o uso das tecnologias de comunicação, tornou-se possível também a visita virtual, que tem um importante papel durante o período de internação hospitalar do paciente com COVID-19. É uma estratégia para reduzir o impacto negativo da hospitalização e deixar o paciente menos estressado e mais seguro durante o tratamento. Tanto permite a participação social, com a interação com familiares à 
distância, quanto pode promover o estímulo às funções mentais no processo de reabilitação, como recurso para estímulo cognitivo e prevenção ao delirium.

Para a realização das visitas virtuais numa satisfatória intervenção terapêutico-ocupacional, é necessário observar os seguintes aspectos:

- acordar com a equipe multidisciplinar sobre a visita virtual e possíveis contribuições;

- observar as questões de adequação técnicas do dispositivo eletrônico compatível e da rede de internet;

- utilizar os Equipamentos de Proteção Individual (EPI's) e materiais para proteção do aparelho eletrônico a ser utilizado;

- recorrer ao melhor recurso a escolha do paciente (videochamada, mensagem de áudio, mensagem escrita);

- escolher o aplicativo a ser utilizado;

- acordar horário e quem será o familiar de referência com o paciente e familiares;

- fazer a avaliação cognitiva da pessoa que está sendo atendida;

- $\quad$ aos pacientes que apresentem rebaixamento de nível de consciência, é sugerido que os familiares mandem recados de áudio a serem reproduzidos;

- após realização da visita virtual realizar um feedback com o paciente e os familiares para otimizar próxima intervenção e realinhar os objetivos terapêuticos ocupacionais.

O terapeuta ocupacional é, portanto, um mediador tanto com a família como com o paciente, ao mesmo tempo em que promove o desempenho ocupacional nas AIVDs, em particular no gerenciamento da comunicação.

\section{Saúde do terapeuta ocupacional como trabalhador da saúde}

Embora o cuidar seja uma das mais belas artes da vida, também se constitui uma difícil tarefa. O sofrimento do próximo pode causar sentimento de impotência, compaixão, resignação e estresse em quem cuida. Não é coincidência que as profissões da saúde estão dentre as mais desgastantes emocionalmente, já que o trabalho costuma ser realizado sob muita pressão e os profissionais não podem tomar atitudes precipitadas ${ }^{142}$.

A unidade de tratamento intensivo (UTI), um dos cenários desta pandemia, é considerada pelos profissionais que nela atuam, pelos pacientes e familiares como um dos ambientes mais tensos, desgastantes e traumatizantes de um hospital ${ }^{143}$.

A atuação dos profissionais de saúde, como os terapeutas ocupacionais, é muito importante neste momento atual, mas pode levar à situações estressantes e prejudiciais, seja fisicamente ou mentalmente, estendendo-se aos familiares e às relações interpessoais dos pacientes, uma vez que o trabalho é um elemento da identidade do indivíduo que ultrapassa o tempo de jornada de trabalho e transborda a sua rotina familiar e seu tempo livre ${ }^{144}$.

São recomendações para auxiliar a manter sua saúde física, mental e espiritual durante essa pandemia:

- trabalhar em equipe multiprofissional;

- planejar suas ações;

- valorizar os distintos saberes, respeitando a experiência de cada profissional;

- $\quad$ ter participação ativa nas decisões da equipe;

- criar parcerias, mantendo um bom ambiente de trabalho;

- $\quad$ seguir diretrizes baseadas em evidências científicas.

Em sua vida privada, o terapeuta ocupacional também necessita utilizar algumas ferramentas ou estratégias de enfrentamento:

- reorganizar a vida cotidiana de acordo com suas prioridades;

- planejar a rotina diária dentro dos novos desafios;

- respeitar seus limites físicos e horas de sono necessárias ao bom funcionamento fisiológico;

- preservar sua dignidade, autonomia e independência;

- manter seus direitos ocupacionais e de participação social;

- preservar seu corpo ativo, criativo e produtivo; 
- preservar os hábitos de trabalho os mais próximos do habitual;

- $\quad$ em caso de home-office, definir as atividades que deverão ser feitas no dia e respeitar o horário de trabalho planejado (não trabalhar mais que o tempo planejado para terminar alguma atividade);

- respeitar-se, pois todos estão em um momento difícil; lembrar que o estresse pode causar dificuldade de atenção e de concentração e queda de produtividade;

- preservar momentos para o descanso, sono e lazer e para o convívio com seus familiares, essenciais para a manutenção da saúde mental, necessária para enfrentar o período de distanciamento social, sempre respeitando as medidas de segurança exigidas;

- lembrar de fazer pausas durante o trabalho para descanso, hidratação e alimentação;

- manter seus rituais e práticas espirituais, como orações, meditações, participação em cultos;

- $\quad$ preservar seu sentido de vida e procurar ajuda, se precisar;

- caso se contamine, fazer escolhas quanto a sua vida, sobre seu tratamento e sobre seu processo de morte.

Quando a morte de um paciente ocorre, o terapeuta deve ter métodos apropriados para promover o fechamento profissional e pessoal do processo, a fim de evitar o desgaste emocional. A reflexão profissional sobre os resultados da terapia fornecida e a confiança nas próprias crenças e valores pessoais/ espirituais são habilidades essenciais para os terapeutas que trabalham em cuidados paliativos.

Por fim, os profissionais de saúde, dentre eles terapeutas ocupacionais, devem ser capazes de gerenciar seus próprios medos e sentimentos sobre doenças graves e morte, a fim de fornecer apoio eficaz aos pacientes e suas famílias. Precisam abordar e, algumas vezes, compartilhar emoções intensas dos pacientes e das famílias para poder ajudá-los a administrar essa lacuna entre esperança e realidade à medida que a doença progride, sem perder-se no sofrimento inevitável, mas que pode ser manejado para a preservação da sua própria saúde física, mental e espiritual.

\section{CONSIDERAÇÕES FINAIS}

Estas diretrizes para o manejo clínico em pacientes com a COVID-19 foram desenvolvidas por terapeutas ocupacionais especialistas em suas áreas de atuação, baseadas nas evidências científicas disponíveis. São recomendações para a prática clínica que podem gerar uma assistência segura, mais eficiente e de qualidade. Contudo, por se tratar de uma doença de grande incidência e de descoberta recente, estas diretrizes poderão ser modificadas com a maior e melhor compreensão da doença e de suas consequências.

Como disseram Morrison e Silva (2020) ${ }^{145}$, ninguém antes imaginava que viveríamos uma pandemia como a da COVID-19. Foi necessária a reestruturação da vida cotidiana de todas as pessoas com a consequente privação ocupacional, devido às medidas de isolamento e distanciamento social.

Os terapeutas ocupacionais que assistem os pacientes com COVID-19, ou mesmo que atuam em contextos de risco de contaminação, também tiveram que se adaptar ao oferecimento da assistência à distância através de teleatendimento, teleconsulta ou telerreabilitação. Esses terapeutas modificaram as suas práticas com novas formas e tecnologias de tratamento, associadas à estratégias na direção da saúde mental, para minimizar os impactos e efeitos das sequelas e diminuir o tempo de hospitalização, como também para promover cuidados interprofissionais que humanizem o trabalho e apoiem as famílias até os cuidados no final da vida e elaboração do luto, durante e após a pandemia.

O terapeuta ocupacional pode assistir o paciente positivo para o coronavírus e sua família nos diferentes níveis de atenção à saúde, desde o diagnóstico, durante a hospitalização, até durante a reabilitação e/ou cuidados paliativos. Deve manter o foco nas ocupações e na ressignificação da vida ocupacional durante todo o tratamento, incluindo o uso de novas tecnologias e modificações na vida ocupacional pós-hospitalização, e poderá atender, inclusive, suas necessidades pós-pandemia.

Mesmo que o paciente seja declarado "livre da doença", o que se tem observado com a 
evolução da pandemia é que ele poderá ter sequelas da COVID-19, como problemas respiratórios, fadiga crônica, dores articulares e problemas cardíacos ou ainda alterações emocionais e piora na qualidade de vida. A experiência atual indica que mesmo pacientes assintomáticos poderão desenvolver complicações de saúde posteriores, mas ainda não há informações ou estudos suficientes sobre isso.

Tudo indica que estamos apenas no início dessa jornada e os terapeutas ocupacionais contribuirão de forma relevante para a superação dos novos desafios impostos pela pandemia da COVID-19. Estas diretrizes serão igualmente úteis para futuras situações epidêmicas que exijam isolamento social, ainda que não seja em nível global, permitindo respostas mais rápidas dos terapeutas ocupacionais.

\section{LIMITAÇÕES}

Dada a recente apresentação da COVID-19, as orientações clínicas podem mudar à medida que se aprende mais sobre essa doença e suas consequências. Assim, será necessário um acompanhamento dos sobreviventes para a atenção às suas necessidades de reabilitação pós-hospitalização e pós-pandemia.

As recomendações desta publicação não substituem as políticas institucionais e nacionais, nem excluem a necessidade do raciocínio clínico para o planejamento e implementação da assistência aos pacientes e/ou seus familiares e cuidadores. Novas evidências científicas que alterem as recomendações aqui contidas poderão ser publicadas posteriormente em novos documentos de diretrizes para a prática profissional.

\section{CONFLITOS DE INTERESSES}

O desenvolvimento destas diretrizes não incluiu nenhuma contribuição financeira ou não financeira da indústria, serviços ou outros. Nenhum dos autores recebeu honorários ou remunerações por qualquer função no processo de desenvolvimento das diretrizes. Portanto, não há conflitos de interesses.

\section{APOIO}

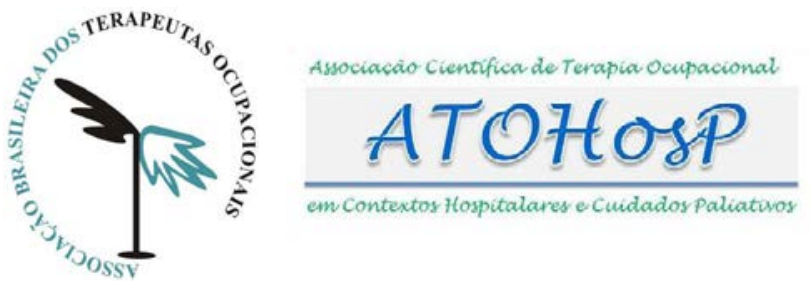

\section{REFERÊNCIAS}

1. Lisboa TC, Cavalcanti AB, Lobo SMA. Diretrizes brasileiras em terapia intensiva: vamos encarar este desafio. Rev Bras Ter Intensiva. 2016; 28(3): 213-214.

2. American Occupational Therapy Association (AOTA). Occupational therapy practice framework: domain and process fourth edition. The American Journal of Occupational Therapy. 2020; 74 (Suppl 2). DOI: https:// doi.org/10.5014/ajot.2020.74S2001.

3. American Occupational Therapy Association A. Estrutura da prática da terapia ocupacional: domínio \& processo. $3^{a}$ ed. traduzida. Rev Ter Ocup Univ São Paulo. 2015; 26(esp): 1-9. DOI: https://doi.org/10.11606/ issn.2238-6149.v26iespp1-49

4. Organização Mundial da Saúde (OMS). Preguntas y respuestas sobre la enfermedad por coronavirus (COVID-19) [Internet]. c2020; Disponível em: https://www.who. int/es/emergencies/diseases/novel-coronavirus-2019/ advice-for-public/q-a-coronaviruses

5. Asadi-Pooya AA, Simani L. Central nervous system manifestations of COVID-19: a systematic review. Journal of the Neurological Sciences. 2019; 413. DOI: https://doi. org/10.1016/j.jns.2020.116832

6. Jahanshahlua L, Rezaeic N. Central Nervous System Involvement in COVID-19. Elsevier Arch Med Res. 2020; 22 (20). DOI: https://doi.org/10.1016/j. arcmed.2020.05.016.

7. Ministério da Saúde (BR). Portaria no 188, de 3 de fevereiro de 2020. Declara Emergência em Saúde Pública de importância Nacional (ESPIN) em decorrência da Infecção Humana pelo novo Coronavírus (2019-nCoV). Diário Oficial da União. 4 de fevereiro de 2020. Seção 1: extra. Disponível em: https://www.in.gov.br/web/dou/-/ portaria-n-188-de-3-de-fevereiro-de-2020-241408388

8. Brasil. Decreto $n^{\circ}$ 7.616, de 17 de novembro de 2011. Dispõe sobre a declaração de Emergência em Saúde Pública de Importância Nacional - ESPIN e institui a Força Nacional do Sistema Único de Saúde - FN-SUS. 17 nov 2011. Seção 1.

9. Hammell KW. Egagement in living during the COVID-19 pandemic and ensuing occupational disruption. Ottawa, Canada: Canadian Association of Occupational Therapist; 2020. Disponível em: http://caot.ca/document/7179/ Ensuring\%20occupational\%20disruption.pdf 
10. Malfitano, APS, Cruz, DMC, Lopes RE. Terapia ocupacional em tempos de pandemia: seguridade social e garantias de um cotidiano possível para todos. Cad Bras de Ter Ocu. 2020; 28(2): 401-404. DOI: https://doi. org/10.4322/2526-8910.ctoED22802

11. Mynard L. Normal life has been disrupted: managing the disruption caused by COVID-19. An Occupational Therapy Guide I; 2020. Disponível em: https://otaus. com.au/publicassets/af469002-6f6a-ea11-9404005056 be 13 b5/OT\%20Guide \% 20COVID-19\%20 March\%202020.pdf

12. World Federation of Occupational Therapists (WFOT). Occupational Therapy and the COVID-19 Pandemic: information and resources. 2020. Disponível em: https:// www.wfot.org/news/2020/occupational-therapy-response-to-the-covid-19-pandemic?fbclid=IWAR175RQWbfORjrIi0-ocGMP1BfeyJDOEvP6HYHWfkZOk1LyJylkMJKboHD8

13. World Federation of Occupational Therapists (WFOT). COVID-19 pandemic: information and resources for occupational therapists. 2020. Disponível em: https:// www.wfot.org/covid-19-information-and-resources-for-occupational-therapists

14. Conselho Federal de Fisioterapia e Terapia Ocupacional (COFFITO). Resolução no 425, de 08 de julho de 2013. Estabelece o Código de Ética e Deontologia da Terapia Ocupacional. COFFITO. 01 de agosto de 2013. Seção 1. Disponível em: https://www.coffito.gov.br/ nsite/?p=3188

15. Galvão CM, Sawada NO, Mendes IAC. A busca das melhores evidências. Revista da escola de enfermagem da USP. 2003; 37(4): 43-50. DOI: https://doi. org/10.1590/S0080-62342003000400005

16. Bennett S, Bennett JW. The process of evidence-based practice in occupational therapy: Informing clinical decisions. Australian Occupational Therapy Journal. 2000; 47: 171-180. DOI: https://doi. org/10.1046/j.1440-1630.2000.00237.x

17. Dijkers MP, Murphy SL, Krellman J. Evidence-based practice for rehabilitation professionals: concepts and con-troversies. Arch Phys Med Rehabil. 2012; 93(8 Suppl 2):S164-76. DOI: 10.1016/j.apmr.2011.12.014

18. Leung EKH. Evidence-based Practice In Occupational Therapy, Journal of Occupational Therapy, Hong Kong, $2002 ; 12(1): 21-32$.

19. Eva G. Necessidade de pesquisa e evidências de terapia ocupacional em cuidados paliativos. In: De-Carlo MMRP, Kudo AM, organizadores. Terapia ocupacional em contextos hospitalares e cuidados paliativos. São Paulo: Payá; 2018, p. 399-411.

20. Ilott I, Taylor MC, Bolanos C. Evidence-based occupational therapy: it's time to take a global approach. The british journal of occupational therapy. 2006; 69(1): 38-41. DOI: $10.1177 / 030802260606900107$

21. Thomas P, Baldwin C, Bisset B, Boden I, Gosselink R, Granger $C L$, et al. Physiotherapy management for COVID-19 in the acute hospital setting: clinical practice recommendations. Journal of Physiotherapy.
2020; 66(2): 73-82. DOI: https://doi.org/10.1016/j. jphys.2020.03.011

22. Thomas $P$, Bisset $B$, Boden $I$, Gosselink R, Granger $C L$, et al. Physiotherapy Management for COVID-19 in the Acute Hospital Setting: Recommendations to guide clinical practice. Pneumon. 2020; 33(1). DOI: https://doi. org/10.1016/j.jphys.2020.03.011

23. Serrano-Castro PJ, Estivill-Torrús G, Cabezudo-García P, Reyes-Bueno JA, Ciano Petersen N, Aguilar-Castillo $\mathrm{MJ}$ et al. Impact of SARS-CoV-2 infection on neurodegenerative and neuropsychiatric diseases: A delayed

pandemic? Neurología. 2020; 35(4): 245-25. DOI: https://doi.org/10.1016/j.nrleng.2020.04.002

24. Mao L, Wang M, Chen S, He Q, Chang C, Zhou Y et al. Neurological Manifestations of Hospitalized Patients with COVID-19 in Wuhan, China: a retrospective case series study. medRxyv. 2020. DOI: https://doi.org/10.1101/2 020.02.22.20026500

25. Colegio Profesional de Terapeutas Ocupacionales de la Comunidad de Madrid (COPTOCAM). Guía clínica de intervención de terapia ocupacional en pacientes con COVID-19. 2020: 47p. [acesso em 12 set 2020]. Disponível em: https://coptocam.org/wp-content/uploads/2020/05/Gu\%C3\%ADa-cl\%C3\%ADnica-de-TOcovid-19-.pdf

26. Healthcare Leadership Blog [Internet]. The Pandemic's 4th Wave. Healthcare Leadership Blog; c2020 [acesso em 12 set 2020]. Disponível em https://hcldr.wordpress.com/2020/04/07/the-pandemics-4th-wave/

27. Royal College of Occupational Therapists (RCOT) [Internet]. A quick guide for occupational therapists: rehabilitation for people recovering from COVID-19; 2020 [acesso em 12 set 2020]. Disponível em: https:// www.rcot.co.uk/node/3474

28. World Health Organization (WHO) [Internet]. Personal protective equipment; 2020. Disponível em: https:// www.who.int/medical_devices/meddev_ppe/en/

29. De-Carlo MMRP, Kebbe LM, Palm RCM. Fundamentação e processos da terapia ocupacional em contextos hospitalares e cuidados paliativos In: De-Carlo MMRP, Kudo AM, organizadores. Terapia Ocupacional em Contextos Hospitalares e Cuidados Paliativos, São Paulo: Ed. Payá; 2018, p. $20-x$

30. Teixeira P, Valle S. Biossegurança: uma abordagem multidisciplinar. $2^{a}$ ed revisada. Rio de Janeiro: Ed. Fiocruz, 2010.

31. Fundação Oswaldo Cruz (Fiocruz), Instituto Fernandes Figueira. Biossegurança Hospitalar (Qualidade e Biossegurança). [acesso em 10 de abr de 2016]. Disponível em: http://www.fiocruz.br/biossegurancahospitalar/principal.htm

32. Agência Nacional de Vigilância Sanitária (ANVISA). Manual de Segurança no Ambiente Hospitalar [Internet]; 2003 [acesso em 12 set 2020]. Disponível em: http:// www.anvisa.gov.br/servicosaude/manuais/seguranca_ hosp.pdf 
33. Cansian TM. A enfermagem e o controle da infecção cruzada. Rev Bras Enferm. 1977; 30(4): 412-22. DOI: https://doi.org/10.1590/0034-716719770004000009

34. Kampf G, Todt D, Pfaender S, Steinmann E. Persistence of coronaviruses on inanimate surfaces and their inactivation with biocidal agentes. Journal of Hospital Infection. 2020; 104(3):246-251. DOI: https://doi. org/10.1016/j.jhin.2020.01.022

35. Salles MM, Matsukura TS. Estudo de revisão sistemática sobre o uso do conceito de cotidiano no capo da terapia ocupacional no Brasil. Cad. Ter. Ocup. UFSCar. 2013; 21(2): 265-273. Disponível em: http://www.cadernosdeterapiaocupacional.ufscar.br/index.php/cadernos/ article/viewFile/928/598

36. Salles MM, Barros S. Representações sociais de usuários de um Centro de Atenção Psicossocial e pessoas de sua rede sobre doença mental e inclusão social. Saúde soc. 2013; 22(4): 1059-1071. DOI: http://dx.doi. org/10.1590/S0104-12902013000400009.

37. Costa $C M L$, Silva $A P L L$, Flores $A B$, Lima $A A$, Poltronieri BC. O valor terapêutico da ação humana e suas concepções em terapia ocupacional. Cad. Ter. Ocup. 2013; 21(1): 195-203. DOI: http://dx.doi.org/10.4322/ cto. 2013.008

38. Rudman DL. Occupational therapy and occupational science: building critical and transformative aliances. Cad Bras Ter Ocup. 2018; 26(1): 241-249. DOI: https:// doi.org/10.4322/2526-8910.ctoEN1246

39. Bezerra A, Silva CEM, Soares FRG, Silva JAM. Fatores associados ao comportamento da população durante o isolamento social na pandemia de COVID-19. Cien Saude Colet. 2020; 25(1): 2411-2421. DOI: http://dx. doi.org/10.1590/1413-81232020256.1.10792020

40. World Health Organization. Mental health and psychosocial considerations during the COVID-19 outbreak. 2020. Disponível em: https://www.who.int/docs/default-source/coronaviruse/mental-health-considerations.pdf

41. Keesing S, Rosenwax $L$, Is occupation missing from occupational therapy in palliative care? Aust Occup Ther J. 2011; 58(5): 329-36. doi: 10.1111/j.1440-1630.2011.00958.x

42. Whiteford G. Occupational Deprivation: Global Challenge in the New Millennium. British Journal of Occupational Therapy. 2000; 63(5): 200-204. DOI: https://doi. org/10.1177/030802260006300503

43. Coelho $T$, Bernardo A, Rocha N, Portugal P. Impacto da privação ocupacional no quotidiano de mulheres reclusas e na sua adaptação à reclusão. In: 1st ICH GaiaPorto; 2010; Porto: Portugal. Porto: Instituto Politécnico do Porto. Escola Superior de Tecnologia da Saúde do Porto (PT); 2010. Disponível em: http://hdl.handle. net/10400.22/1408

44. Cruz E. Papéis ocupacionais de pessoas com deficiências físicas: diferenças de gênero e ciclos de desenvolvimento. Revista Baiana de Terapia Ocupacional. 2012; 1(1): 4-24. Disponível em: https://www5.bahiana.edu.br/ index.php/terapiaocupacional/article/view/124
45. Weinstock-Zlotnick G, Mehta SP. A systematic review of the benefits of occupation-based intervention for patients whit upper extremity musculoskeletal disordes. Journal of Hand Therapy. 2019; 32(2): 141-152. DOI: 10.1016/j.jht.2018.04.001

46. Rothan HA, Byrareddy SN. The epidemiology and pathogenesis of coronavirus disease (COVID-19) outbreak. Journal of autoimmunity. 2020; 109: 102433. DOI: https://doi.org/10.1016/j.jaut.2020.102433

47. Falvey JR, Krafft C, Kornetti D. The essential role of home-and community-based physical therapists during the COVID-19 pandemic. Physical Therapy. 2020; 00(7):1058-1061. DOI: 10.1093/ptj/pzaa069.

48. Nicola M, Alsafi Z, Sohrabi C, Kerwan A, Al-Jabir A, Iosifidis $C$, et al. The socio-economic implications of the coronavirus and COVID-19 pandemic: a review. International Journal of Surgery. 2020; 78: 185-193. DOI: $10.1016 /$ j.ijsu.2020.04.018

49. Othero MB. Terapia ocupacional na atenção extra-hospitalar oferecida pelo hospital. Cadernos Brasileiros de Terapia Ocupacional. 2012; 20(2): 195-202. DOI: http://dx.doi.org/10.4322/cto.2012.019

50. Ministério da Saúde (BR). Portaria no 2.436, de 21 de setembro de 2017. Aprova a Política Nacional da Atenção Básica, estabelecendo a revisão de diretrizes para a organização da Atenção Básica, no âmbito do Sistema Único de Saúde (SUS). Diário Oficial da União. 22 set 2017; Seção 1. Disponível em: https://www.in. gov.br/materia/-/asset_publisher/Kujrw0TZC2Mb/content/id/19308123/do1-2017-09-22-portaria-n-2-436de-21-de-setembro-de-2017-19308031

51. Starfield DB. Atenção Primária: equilíbrio entre necessidades de saúde, serviços e tecnologias. Brasília: UNESCO/Ministério da Saúde; 2002. Disponível em: https://www.nescon.medicina.ufmg.br/biblioteca/imagem/0253.pdf

52. Mendes EV. As redes de atenção à saúde. Brasília: Organização Pan-Americana da Saúde; 2011.

53. Silva RAS, Menta SA. Abordagem de terapeutas ocupacionais em Núcleos de Apoio à Saúde da Família (NASF) no estado de Alagoas. Cadernos de Terapia Ocupacional da UFSCar. 2014; 22(2): 243-250. DOI: https://doi. org/10.4322/cto.2014.046

54. Rajão FL, Martins M. Atenção Domiciliar no Brasil: estudo exploratório sobre a consolidação e uso de serviços no Sistema Único de Saúde. Ciência \& Saúde Coletiva. 2020; 25: 1863-77. DOI: https://doi. org/10.1590/1413-81232020255.34692019

55. Frizzo HCF, Corrêa VAC. Terapia ocupacional em contextos hospitalares: a especialidade, atribuições, competências e fundamentos. Refacs. 2018; 6(1): 130-139. DOI: https://doi.org/10.18554/refacs.v6i1.2379

56. Moreira LC, Costa TSMA, Fonsêca GS. Clínica Ampliada. In: Semana Acadêmica do Curso de Medicina da Universidade Federal da Fronteira Sul; 19-21 set. 2019; Fronteira do Sul. Fronteira do Sul (SC): Universidade Federal da Fronteira Sul ;2019; 2(2). Disponível em: 
https://portaleventos.uffs.edu.br/index.php/SUE/ article/view/12152/9177

57. Campos GWS, Amaral MA. A clínica ampliada e compartilhada, a gestão democrática e redes de atenção como referenciais teórico-operacionais para a reforma do hospital. Ciência \& Saúde Coletiva. 2007; 12(4): 849-59. DOI: https://doi.org/10.1590/ S1413-81232007000400007

58. De Carlo MMRP, Kudo AM, organizadores. Terapia ocupacional em contextos hospitalares e Cuidados Paliativos. São Paulo: Editora Payá; 2018.

59. Hui D, Wong K, Antonio G, Tong M, Chan D, Sung J. Long-term sequelae of SARS: physical, neuropsychiatric, and quality-of-life assessment. Hong Kong medical journal= Xianggang yi xue za zhi. 2009; 15:21. Disponível em: https://www.hkmj.org/system/files/ hkm0912sp8p21.pdf

60. Lau HM-C, Lee EW-C, Wong CN-C, Ng GY-F, Jones AY-M, Hui DS-C. The impact of severe acute respiratory syndrome on the physical profile and quality of life. Archives of physical medicine and rehabilitation. 2005;86(6):1134-40. DOI: https://doi.org/10.1016/j. apmr.2004.09.025

61. Jiménez-Pavón D, Carbonell-Baeza A, Lavie CJ. Physical exercise as therapy to fight against the mental and physical consequences of COVID-19 quarantine: Special focus in older people. Progress in cardiovascular diseases. 2020; 63(3): 386-388. DOI: $10.1016 / \mathrm{j}$. pcad.2020.03.009

62. Kerber NPdC, Kirchhof ALC, Cezar-Vaz MR. Considerações sobre a atenção domiciliária e suas aproximações com o mundo do trabalho na saúde. Cadernos de Saúde Pública. 2008; 24: 485-93.

63. Conselho Federal de Fisioterapia e Terapia Ocupacional (COFFITO). Resolução no 371, de 06 de novembro de 2009. Dispõe sobre a alteração do artigo $1^{0}$ da Resolução COFFITO no 366. COFFITO. 30 de novembro de 2009. Seção 1. Disponível em: https://www.coffito. gov.br/nsite/?p=3134

64. Conselho Federal de Fisioterapia e Terapia Ocupacional (COFFITO). Resolução no 429, de 08 de julho de 2013. Reconhece e disciplina a especialidade de Terapia Ocupacional em Contextos Hospitalares, define as áreas de atuação e as competências do terapeuta ocupacional especialista em Contextos Hospitalares e dá outras providências. COFFITO. 02 de setembro de 2013. Seção 1. Disponível em: https://www.legisweb.com.br/ legislacao/?id $=258100$

65. Spruit MA, Singh SJ, Garvey C, ZuWallack R, Nici L, Rochester C, et al. An official American Thoracic Society/ European Respiratory Society statement: key concepts and advances in pulmonary rehabilitation. Am J Respir Crit Care Med. 2013; 1888(8): 13-64. DOI: 10.1164/ rccm.201309-1634ST

66. Ministério da Saúde (BR). Secretaria de Atenção Especializada à Saúde. Departamento de Atenção Hospitalar, Domiciliar e de Urgência. Protocolo de manejo clínico da Covid-19 na Atenção Especializada. 2020.
Disponível em: https://bvsms.saude.gov.br/bvs/publicacoes/manejo_clinico_covid-19_atencao_especializada.pdf

67. Othero MB. Terapia ocupacional na atenção extra-hospitalar oferecida pelo hospital. Cadernos Brasileiros de Terapia Ocupacional. 2012; 20(2): 195-202. DOI: http://dx.doi.org/10.4322/cto.2012.019

68. Ministério da Saúde (BR). Resolução $n^{\circ} 7$, de 24 de fevereiro de 2010. Dispõe sobre os requisitos mínimos para funcionamento de Unidades de Terapia Intensiva e dá outras providências. Diário Oficial da União. 25 de fevereiro de 2010. Seção 1. Disponível em: https:// www.saude.mg.gov.br/images/documentos/RDC-7_ ANVISA\%20240210.pdf

69. Schujmann DS. Imobilismo e inatividade no hospital e na Unidade de Terapia Intensiva. In: Schujmann DS, Fu C. Reabilitação e Mobilização Precoce em UTI - Princípios e práticas. Barueri: Manole; 2019. p.1-6.

70. Carmo GP, Nascimento JS, Dos Santos TRM, Coelho PSO. Intervenções terapêutico-ocupacionais para pacientes com COVID-19 na UTI. Rev. Interinst. Bras. Ter. Ocup. Rio de Janeiro. 2020; 4(3): 397-415. DOI: https://doi. org/10.47222/2526-3544.rbto33997

71. Joseph $T$, editor. International Pulmonologist's Consensus on COVID-19. $2^{\text {a }}$ edição. 2020.

72. Pelosi MB, Gomes CA. Tecnologia Assistiva e Terapia Ocupacional no Contexto Hospitalar. In: De Carlo, MMRP, Kudo AM, organizadores. Terapia Ocupacional em Contextos Hospitalares e Cuidados Paliativos. São Paulo: Editora Payá. 2018; p. 103-126.

73. Barbas CSV, Isola AM, Farias AMC, organizadores. Diretrizes Brasileiras de Ventilação Mecânica. Brasil: Associação de Medicina Intensiva Brasileira (AMIB), Sociedade Brasileira de Pneumologia e Tisiologia (SBPT). 2013. Disponível em: https://www.amib. org.br/fileadmin/user_upload/amib/2018/junho/15/ Diretrizes_Brasileiras_de_Ventilacao_Mecanica_2013_ AMIB_SBPT_Arquivo_Eletronico_Oficial.pdf

74. Comitê de Ventilação Mecânica da Associação de Medicina Intensiva Brasileira. Manuseio do paciente com infecção pelo Coronavírus COVID-19 e pneumonia e insuficiência respiratória. 2020. Disponível em: https:// www.amib.org.br/fileadmin/user_upload/amib/2020/ marco/12/carta_corona_ventilacao_mecanica.pdf

75. Paiva KCA, Beppu OS. Posição Prona. J BrasPneumol. 2005; 31(4): 332-40. DOI: https://doi.org/10.1590/ S1806-37132005000400011

76. Pelosi MB. Comunicação Alternativa e Suplementar. In: Cavalcanti A, Galvão C, organizadores.Terapia Ocupacional: Fundamentação \& Prática. Rio de Janeiro: Guanabara Kogan, 2007. p. 462-468.

77. Pitrowsky MT, Shinotsuka CR, Soares M, Lima MASD, Salluh, JIF. Importância da monitorização do delirium na unidade de terapia intensiva. Ver Bras Ter Intensiva. 2010; 22(3): 274-279. DOI: https://www.scielo.br/pdf/ rbti/v22n3/10.pdf 
78. Barbosa FDS, Reis MCS. O papel da Terapia Ocupacional nas Unidades de Terapia Intensiva: uma revisão de literatura. Rev. Interinst. Bras. Ter. Ocup. 2017; 1(2): 221-239. DOI: https://doi.org/10.47222/2526-3544. rbto 4753

79. Rodriguez-Morales AJ, Cardona-Ospina JA, GutiérrezOcampo $E$, et al. Clinical, laboratory and imaging features of COVID-19: A systematic review and meta-analysis. Travel Medicine and Infectious Disease. 2020; 34:101623. DOI: $10.1016 /$ j.tmaid.2020.101623

80. Herridge MS, Moss $M$, Hough $C L$, et al. Recovery and outcomes after the acute respiratory distress syndrome (ARDS) in patients and their family caregivers. Intensive care medicine. 2016; 42(5): 725-38. DOI: $10.1007 / \mathrm{s} 00134-016-4321-8$

81. Wade DT. Describing rehabilitation interventions. Clin Rehabil. 2005; 19(8): 811-818. DOI: 10.1191/0269215505cr923ed

82. Kho ME, Brooks D, Namasivayam-Macdonald A, Sangrar R, Vrkljan, B. Rehabilitation for patients with COVID-19: guidance for occupational therapists, physical therapists, speech-language pathologists and assistants. School of Rehabilitation Science. 2020. Disponivel em: https://srs-mcmaster.ca/wp-content/uploads/2020/04/Rehabilitation-for-Patients-with-COVID19-Apr-08-2020.pdf

83. Simpson R, Robinson L. Rehabilitation After Critical Illness in People With COVID-19 Infection. Am J Phys Med Rehabil. 2020; 99(6): 470-474. DOI: 10.1097/ PHM.0000000000001443

84. Winstein $\mathrm{CJ}$, Wolf SL, Dromerick AW, Lane CJ, Nelsen $M A$, et al. Effect of a Task-Oriented Rehabilitation Program on Upper Extremity Recovery Following Motor Stroke: The ICARE Randomized Clinical Trial. JAMA. 2016; 315(6): 571-581. DOI: 10.1001/jama.2016.0276

85. Hocking, C. Process of assessment and evaluation. In: Curtin, M; Molineux, J. S.-M. (Ed.). Occupational Therapy and Physical Dysfunction Enabling Occupation. 6. ed. Edinburgh; New York: Churchill Livingstone Elsevier, p. 81-94, 2010

86. Brown GT, Chien, CW. Top-down or Bottom-up occupational therapy assessment: which way do we go? British Journal of Occupational Therapy. 2010; 73(3): 95-95. DOI:

87. Mendes PVB. Adaptação transcultural e propriedades psicométricas do "Occupational Self Assessment" para a língua portuguesa do Brasil. [tese]. São Carlos: Centro de Ciências Biológicas e da Saúde; 2020. Disponível em: https://repositorio.ufscar.br/bitstream/handle/ufscar/12713/Tese\%20Mendes\%20PVB\%202020. pdf?sequence $=1$

88. Held N, Moss M. Optimizing Post-Intensive Care Unit Rehabilitation. Turk Thorac J. 2019; 20(2): 147-152. DOI: $10.5152 /$ TurkThoracJ.2018.18172

89. Richards LG, Latham NK, Jette DU, Rosenberg L, Smout RJ, Dejong G. Characterizing occupational therapy practice in stroke rehabilitation. Arch Phys Med
Rehabil. 2005; 86(12 Suppl 2): 51-60. DOI:10.1016/j. apmr.2005.08.127

90. Weinreich M, Herman J, Dickason $S$, Mayo $H$. Occupational therapy in the intensive care unit: a systematic review. Occup Ther Health Care. 2017; 31(3): 205-213. Doi:10.1080/07380577.2017.1340690

91. Velloso M, Jardim JR. Funcionalidade do paciente com doença pulmonar obstrutiva crônica e técnicas de conservação de energia. J bras pneumol. 2006; 32(6): 580-586. DOI: https://doi.org/10.1590/ S1806-37132006000600017

92. Ogden LD, Deveene C. COPD program guidelines for occupational therapists and other health professionals. In: O'Dell-Rossi P, Browning G, Barry J. Occupational therapy in pulmonary rehabilitation. Maryland: Ramsco; 1985. p. $50-8$

93. International Association for Hospice \& Palliative Care (IAHPC). Consensus Based Palliative Care Definition. c2020. Disponível em: https://hospicecare. com/what-we-do/projects/consensus-based-definitionof-palliative-care/

94. Radbruch L, De Lima L, Knaul F, Wooodruff R, Yong J, Pastrana T. Redefining palliative care: a new consensus-based definition. Journal of Pain and Symptom Management. 2020. DOI: https:// doi.org/10.1016/j. jpainsymman.2020.04.027

95. Ballentine JM. The role of palliative care in a COVID-19 pandemic: palliative care strengths such as communication, advance care planning, and symptom management, needed now more than ever. CSU Palliative Care. Palliative Care Education: anytime, anywhere. Disponível em: https://csupalliativecare.org/ palliative-care-and-covid-19/

96. World Health Organization. Clinical management of COVID-19: interim guidance. 2020. Disponívelem: https:// www.who.int/publications/i/item/clinical-managementof-covid-19

97. Rajagopal MR, Connor S, Gray D, Luz R, Marston J, Ross $\mathrm{K}$, et al. Declaration and call-to-action on palliative care \& COVID-19. Elisabeth Kübler-Ross Foundation. 2020. Disponível em: https://www.ekrfoundation.org/declaration-and-call-to-action-on-palliative-care-covid-19/

98. Bye RA. When clients are dying, occupational therapy perspective. Occupational Therapy Research. 1998; 18: 3-24. DOI: https://doi.org/10.1177/ 153944929801800101

99. Elisabeth Kübler-Ross Foundation. Curva da Mudança Kübler-Ross. c2020. Disponível em: https://www.ekrfoundation.org/5-stages-of-grief/change-curve/

100. Mystakidou K, Tsilika E, Parpa E, Pathiak M, Patiraki E, Galanos A, et al. Exploring the relationships between depression, hopelessness, cognitive status, pain, and spirituality in patients with advanced cancer. Arch Psychiatr Nurs. 2007; 21(3): 150-161. DOI: 10.1016/j. apnu.2007.02.002

101. De Carlo MMRP, Kebbe LM, Palm RDCM. Fundamentação e processos da terapia ocupacional em contextos 
hospitalres e cuidados paliativos. In: De Carlo MMRP, Kudo AM, organizadores. Terapia ocupacional em contextos hospitalares e cuidados paliativos. São Paulo: Payá; 2018. p. 2-32.

102. Martoni AA, Varani S, Peghett B, Roganti D, Volpicella E, Pannuti $R$, et al. Spiritual well-being of Italian advanced cancer patients in the home palliative care setting. Eur J Cancer Care 2017; 26(4):1-9. DOI: 10.1111/ecc.12677

103. Anandarajah G, Hight E. Spirituality and medical practice: using the HOPE Questions as a practical tool for spiritual assessment. Am Fam Physician. 2001; 63(1): 81-89. Disponível em: https://www.aafp.org/ afp/2001/0101/p81.html

104. Koenig HG, Mccullough,ME, Larson DB. Handbook of religion and health. Oxford (England): University Press USA; 2001.

105.De Carlo MMRP, Queiroz MEG, Santos WA. Terapia ocupacional em dor e cuidados paliativos: princípios, modelos de intervenção e perspectivas. In: De Carlo MMRP, Queiroz MEG, organizadores. Dor e cuidados paliativos: terapia ocupacional e interdisciplinaridade. São Paulo: Roca; 2008. p. 126-145.

106. Hospice UK. What is rehabilitative palliative care? c2018. Disponívelem: https://www.hospiceuk.org/what-we-offer/ clinical-and-care-support/rehabilitative-palliative-care/ what-is-rehabilitative-palliative-care

107. Gonçalo T, Nascimento JS, Bombarda TB, Espalenza GV, Rodrigues EAA, Ferreira AP, et al. Terapia Ocupacional em Cuidados Paliativos na COVID-29. Comitê de Terapia Ocupacional da Academia Nacional de Cuidados Paliativos; 2020. Disponível em: https://paliativo.org. br/wp-content/uploads/2020/05/TO-CP-COVID19.pdf

108. Parkes CM. Amor e perda: as raízes do luto e suas complicações. São Paulo: Summus, 2009.

109. Tuffrey-Wijne I, Hollins S. When someone dies from coronavirus: a guide for family and carers. London: Beyond Words; 2020. Disponível em https://booksbeyondwords.co.uk/downloads-shop/ when-someone-dies-from-coronavirus

110. Gwyther L, Brennan F, Harding R. Advancing palliative care as a human right. Journal of Pain and Symptom Management. 2009; 38(5): 767-774. DOI: doi. org/10.1016/j.jpainsymman.2009.03.003

111. Raja SN, Carr D, Cohen M, Finnerup N, Flor H, Gibson S, et al. The revised International Association for the Study of Pain definition of pain. PAIN. 2020; 161(9): 19761982. DOI: $10.1097 /$ j.pain.0000000000001939

112. Menni C, Valdes A, Freydim MB, Ganesh S, Moustafa JE, Visconti $A$, et al. Loss of smell and taste in combination with other symptoms is a Strong predictor of COVID-19 infection. MedRvix. 2020. DOI: https://doi.org/10.1101 /2020.04.05.20048421

113. Organização Pan-Americana de Saúde (OPAS) [Internet]. Folha informativa - COVID-19 doença causada pelo novo coronavírus. c2020 [atualizada em 24 abr 2020; acesso 25 abr 2020]. Disponível em: https:// www.paho.org/pt/covid19
114. Pidgeon $T$, Johnson CE, Currow $D$, Yates $P$, Banfield $M$, Lester $L$, et al. A survey of patients' experience of pain and other symptoms while receiving care from palliative care services. BMJ Support Palliat Care. 2016; 6(3): 315-322. DOI: http://dx.doi.org/10.1136/ bmjspcare-2014-000748

115. Satija A, Singh SP, Kashyap K, Bhatnagar S. Management of total cancer pain: a case of young adult. Indian J Palliat Care. 2014; 20(2):153-156. DOI: 10.4103/0973-1075.132651.

116. Saunders C. The evolution of the hospice: the Management of pain; 1990.

117. Lagueux E, Dèpelteau A, Masse J. Occupational Therapy's Unique Contribution to Chronic Pain Management: a scoping review. Pain Res Manag. 2018. DOI: doi.org/10.1155/2018/5378451

118. Skjutar A, Schult ML, Christensson K, Mullersdorf M. Indicators of need for Occupational Therapy in patients with chronic pain: Occupational Therapists'focus groups. Occup. Ther. Int. 2010; 17(2): 93-103. DOI: doi.org/10.1002/oti.282.

119. Hshieh T, Yue J, Oh E, Puelle M, Dowal S, Travison T, et al. Effectiveness of multicomponent nonpharmacological delirium interventions: a meta-analysis. JAMA Intern Med. 2015; 175(4): 512-520. DOI: 10.1001/ jamainternmed.2014.7779

120. Sewell L. Occupational Therapy and Pulmonary Rehabilitation. In: Clini E, Holland AE, Pitta F, Troosters $\mathrm{T}$, coordenadores. Textbook of Pulmonary Rehabilitation [Internet]. Springer International Publishing; 2018.159169. Disponível em: https://link.springer.com/ chapter/10.1007/978-3-319-65888-9_12\#citeas

121. Higginson IJ, Maddocks M, Bayly J, Brighton LJ, Hutchinson $A$, Booth $S$, et al. Managing your breathlessness at home during the coronavirus (COVID-19) outbreak. 2020. Disponível em: https://www.kcl.ac.uk/ cicelysaunders/resources/khp-gp-breathlessness-resource.pdf

122. Macmillan Cancer Support. 8 ed. Coping with fatigue (tiredness): the information Standard. 2018.

123. Ferreira R. Sugestões de posicionamentos para manejo de sintomas. 2020.

124. Royal College of Occupational Therapists (RCOT). How to conserve your energy: practical advice for people during and after having COVID-19. [Internet]. c2020. Disponível em: https://www.rcot.co.uk/ conserving-energy

125. Melvin JL. Rheumatic Diesease in the adult and child: occupational therapy and rehabilitation. Philadelphia: F. A. Davis; 1989. Roles and functions of occupational therapy in the management of patients with rheumatic diseases.

126. De Carlo MMRP, Elui VMC, Packer MP. Terapia ocupacional e atenção ao aciente com dor não-oncológica. In: De Carlo MMRP, Queiroz MEGD. Dor e cuidados paliativos na perspectiva da Terapia Ocupacional. São Paulo: Rosa Ltda; 2008; p.167-190. 
127. Marie Curie. Managing breathlessness: a guide to breathing techniques, medication and other things that can help. 2019. Disponível em: https://www.mariecurie. org.uk/globalassets/media/documents/how-we-can-help/booklets-pdfs-only/managing-breathlessness.pdf

128. Guy's and St Thomas' NHS Foundation Trust. Using your energy wisely. 2020. Disponível em: https://www.guysandstthomas.nhs.uk/resources/patient-information/ cardiovascular/using-your-energy-wisely.pdf

129. Pelosi MB. Proposta de implementação da Comunicação Alternativa e Ampliada nos hospitais do município do Rio de Janeiro. Temas sobre Desenvol. 2005; 14(80/81): 47-53.

130. Portal de Tecnologia Assistiva do Curso de Terapia Ocupacional UFRJ. Comunicação Alternativa: Covid-19. c2020. Disponível em: http://www. portalassistiva.com.br/pranchas/atividades. php?opcao $=4 \&$ cod_atividade $=2916$

131. American Occupational Therapy Association (AOTA). Telerehabilitation. American Journal of Occupational Therapy. 2010； 64: 92-02. DOI: https://doi. org/10.5014/ajot.2010.64S92

132. Cason J. Telehealth opportunities in occupational therapy through the Affordable Care Act. Am J Occup Ther. 2012; 66(2):131-136. DOI: doi.org/10.5014/ ajot.2012.662001

133. Chao LW. Telemedicina e Telessaúde: um panorama no Brasil. Informática Pública. 2008; 10(2): 07-15. Disponível em: http://www.ip.pbh.gov.br/ANO10_N2_ PDF/telemedicina_telesaude.pdf

134. Rodrigues do Prado De-Carlo MM, Figueiredo-Frizzo HC, Kudo AM, Muñoz-Palm RC. Videoconferencing in occupational therapy in hospital contexts and palliative care. Revista de la Facultad De Medicina. 2018; 66: 575-580.

135. Mancini F, Barcelos TS. Ações Educativas em Saúde. Universidade de São Paulo; 2014.

136. World Health Organization. Information technology in support of health care. (2012). [Cited 2012 oct 24]. Disponível em: http://www.who.int/eht/en/ InformationTech.pdf
137. Caffery LJ, Smith AC. A literature review of email-based telemedicine. Stud Health Technol Inform. 2010; 161: 20-34.

138. Novoa CG, Valerio Netto A, organizadores. Fundamentos em gestão e informática em saúde [e-book]. São Paulo: Escola Paulista de Medicina - Universidade de São Paulo; 2019. Disponível em: https://repositorio.unifesp. $\mathrm{br} / \mathrm{handle} / 11600 / 51788$

139. Rezende EJC, Melo MCB, Tavares EC, Santos AF, Souza C. Ética e telessaúde: reflexões para uma prática segura. Rev Panam Salud Publica. 2010; 28(1):58-65. Disponível em: https://iris.paho.org/handle/10665.2/9660

140.Spinardi ACP, Blasca WQ, Wen CL, Maximino LP. Telefonoaudiologia: ciência e tecnologia em saúde. Pró-Fono Revista de Atualização Científica. 2009; 21(3): 249-54. DOI: http://dx.doi.org/10.1590/ S0104-56872009000300012

141. American Ocupational Therapy Association (AOTA) [Internet]. OT and Telehealth in the Age of COVID-19. c2020. Disponivel em: https://www.aota.org/Practice/ Manage/telehealth/coronavirus.aspx

142. Santos FD, Cunha MH, Robazzi MLCC, Pedrão LJ, Silva LA, Terra FS. O estresse do enfermeiro nas unidades de terapia intensiva adulto: uma revisão da literatura. Rev. Eletrônica Saúde Mental Álcool Drog. 2010; 6(1). Disponível em: http://pepsic.bvsalud.org/scielo.php?script=sci_arttext\&pid=S1806-69762010000100014

143. Coronetti A, Nascimento ERP, Barra DCC, Martins JJ. O estresse da equipe de enfermagem na unidade de terapia intensiva: o enfermeiro como mediador. Arquivos Catarinenses de Medicina. 2006; 35(4): 36-43. Disponível em: https://www.acm.org.br/revista/pdf/artigos/394.pdf

144. Cremasco L, Constantini TC, Silva VA. A Farda que é um fardo: o estresse profissional na visão de militares do corpo de bombeiros. Cadernos de Terapia Ocupacional da UFSCar. 2008; 16(2): 83-90. Disponível em: http:// www.cadernosdeterapiaocupacional.ufscar.br/index. php/cadernos/article/view/122

145. Morrison R, Silva C. Terapia ocupacional en tiempos de pandemia. Revista Chilena de Terapia Ocupacional. 2020; 20(1): 7-12. DOI:10.5354/0719-5346.2020.57813 